\title{
EL PROYECTO TERRITORIAL DEL PORFIRIATO EN LA PENÍNSULA DE BAJA CALIFORNIA: ¿Una ocupación urbana a través de company towns?
}

\author{
Enrique Esteban Gómez Cavazos \\ Universitat Politécnica de Catalunya. Doctorado en Urbanismo \\ Director: Joaquín Sabaté Bel \\ Mail: eecavazos@hotmail.com
}

\section{RESUMEN}

En este artículo verificamos la influencia de las company towns en la península de la Baja California y cuánto éstas, pueden considerarse un decisivo instrumento de urbanización de este territorio entre finales del siglo XIX y principios del XX. El gobierno mexicano aprovecha la temprana industrialización en ésta parte del país utilizando una arriesgada estrategia económica sin precedentes: tratar de ocupar a través de enclaves esta larga y angosta península, escasamente poblada. Otorga grandes concesiones territoriales a capitales en su mayoría extranjeros para colonizar esta región a través de grandes industrias que trazan poblados y ciudades industriales. Queremos revisar los proyectos de aquellas compañías que utilizan el modelo de company town. Su importancia reside en valorizar un proyecto territorial que trata con gran esfuerzo de urbanizar y consolidar poblaciones a través de la industrialización, con el indudable apoyó del presidente de México, Porfirio Díaz.

Palabras clave: proyecto territorial, company town, patrimonio industrial

\begin{abstract}
In this article we verify the influence of the company towns in the peninsula of Baja California and how much these, can be considered a decisive instrument of urbanization of this territory between the end of the nineteenth century and early twentieth century. The Mexican government uses the early industrialization in this part of the country and implements a risky economic strategy without precedents: to try to occupy through company towns this long and narrow peninsula, sparsely populated. It grants large territorial concessions to mostly foreign capital to colonize this region through large industries that develops towns and industrial cities. We want to review the projects of those companies that use the company town model. Its importance lies in highlight a territorial project that tries with great effort to urbanize and consolidate populations through industrialization, with the unquestionable support of the President of México, Porfirio Díaz.
\end{abstract}

Keywords: territorial project, company town, industrial heritage 


\section{Introducción}

Durante estos últimos años hemos venido analizando el modelo de urbanización desarrollado en la península de Baja California entre finales del siglo XIX y principios del XX, utilizando las denominadas company towns, con la voluntad de reconocer dicho patrimonio industrial. En este periodo de industrialización se fundan diversas ciudades, diseñadas en su gran mayoría por compañías extranjeras, orientadas principalmente a actividades económicas como la minería industrial, la agroindustria, la explotación salinera y la urbanización. Se reconocen distintos casos de estudio, con la voluntad de proponerlos en un futuro como un conjunto de paisajes culturales y vincularlos a través de una ruta de arquitectura industrial a lo largo del territorio peninsular.

El estudio se centra en los proyectos que realizan las compañías y en su desarrollo hasta nuestros días.

\section{Metodología}

Para abordar los procesos de transformación adopto una metodología de identificación de los valores patrimoniales a escala territorial, urbana y arquitectónica, en un abanico temporal que permita apreciar el arranque de los proyectos y su evolución o despoblamiento.



Figura 1. Línea de tiempo donde se agrupan los 10 casos más representativos de poblaciones diseñadas por compañías en la península de la Baja California. Nota: La mayoría de los casos aparecen en el Porfiriato, pero existen casos que surgen antes y es en el Porfiriato cuando toman un mayor impulso y se consolidan. Hay otros casos que se establecen después pero ya existía alguna actividad económica en dicho periodo. Fuente: Elaboración Propia.

En una primera aproximación los casos se clasifican en función de las compañías, actividades económicas, ocupación y patrimonio industrial (ver tabla 1). 
Tabla 1.

\begin{tabular}{|c|c|c|c|c|c|c|c|c|}
\hline $\begin{array}{l}\text { NOMBRE DE } \\
\text { LA } \\
\text { COMPAÑÍA }\end{array}$ & ACTIVIDAD & DUEÑOS & $\begin{array}{l}\text { NOMBRE } \\
\text { DE LA } \\
\text { POBLACIÓN }\end{array}$ & DURACIÓN & $\begin{array}{l}\text { CAUSA DEL } \\
\text { CIERRE }\end{array}$ & $\begin{array}{l}\text { POBLACIÓN } \\
\text { ACTUAL } \\
\text { APROXIMADA }\end{array}$ & $\begin{array}{l}\text { TIPO DE } \\
\text { PATRIMONIO } \\
\text { INDUSTRIAL }\end{array}$ & OBSERVACIONES \\
\hline $\begin{array}{l}\text { International } \\
\text { Company of } \\
\text { México }\end{array}$ & Urbanización & $\begin{array}{l}\text { Hanbury \& } \\
\text { Garvey Capital } \\
\text { inglés y } \\
\text { norteamericano }\end{array}$ & Ensenada & $1884-1917$ & $\begin{array}{l}\text { Concesión } \\
\text { cancelada por } \\
\text { incumplimiento }\end{array}$ & 519.813 & $\begin{array}{l}\text { Bodegas de } \\
\text { vino }\end{array}$ & $\begin{array}{l}\text { Cuenta con } \\
\text { patrimonio } \\
\text { arquitectónico } \\
\text { "Balloon Frame" }\end{array}$ \\
\hline $\begin{array}{l}\text { Colorado } \\
\text { River Land } \\
\text { Company }\end{array}$ & $\begin{array}{l}\text { Agro- } \\
\text { industria }\end{array}$ & $\begin{array}{l}\text { Harrison Gray } \\
\text { Otis. Dueño de } \\
\text { los Ángeles } \\
\text { Times. Capital } \\
\text { norteamericano }\end{array}$ & Mexicali & 1901-1937 & $\begin{array}{l}\text { Asalto a las } \\
\text { tierras }\end{array}$ & 689.775 & $\begin{array}{l}\text { Canales de } \\
\text { irrigación, } \\
\text { edificios de la } \\
\text { compañía }\end{array}$ & $\begin{array}{l}\text { Centro histórico } \\
\text { muy deteriorado }\end{array}$ \\
\hline $\begin{array}{l}\text { Compagnie } \\
\text { du Boleo }\end{array}$ & Minería & $\begin{array}{l}\text { Familia } \\
\text { Rothschild. } \\
\text { Capital francés }\end{array}$ & $\begin{array}{l}\text { Santa } \\
\text { Rosalía }\end{array}$ & $1885-1956$ & $\begin{array}{l}\text { Mineral } \\
\text { agotado }\end{array}$ & 11.765 & $\begin{array}{l}\text { Fundidora, } \\
\text { edificios y } \\
\text { minas }\end{array}$ & $\begin{array}{l}\text { Rico patrimonio } \\
\text { industrial en } \\
\text { abandono }\end{array}$ \\
\hline $\begin{array}{l}\text { Hanbury \& } \\
\text { Garvey } \\
\text { Company }\end{array}$ & $\begin{array}{l}\text { Agro- } \\
\text { industria }\end{array}$ & $\begin{array}{l}\text { Capital Inglés y } \\
\text { norteamericano }\end{array}$ & San Quintín & $1887-1917$ & $\begin{array}{l}\text { Revolución } \\
\text { Mexicana }\end{array}$ & 4.777 & $\begin{array}{l}\text { Primer molino } \\
\text { de harina }\end{array}$ & $\begin{array}{l}\text { Molino y } \\
\text { construcciones de } \\
\text { la colonia inglesa }\end{array}$ \\
\hline $\begin{array}{l}\text { El Progreso } \\
\text { Mining } \\
\text { Company }\end{array}$ & Minería & $\begin{array}{l}\text { Capital inglés y } \\
\text { norteamericano }\end{array}$ & $\begin{array}{l}\text { El Triunfo y } \\
\text { San } \\
\text { Antonio }\end{array}$ & $1878-1912$ & $\begin{array}{l}\text { Mineral } \\
\text { agotado }\end{array}$ & 321 y 463 & $\begin{array}{l}\text { Chimeneas, } \\
\text { puentes y } \\
\text { edificios }\end{array}$ & $\begin{array}{l}\text { Patrimonio } \\
\text { Industrial en } \\
\text { ruinas }\end{array}$ \\
\hline $\begin{array}{l}\text { Exportadora } \\
\text { de Sal, S.A. } \\
\text { de C.V. }\end{array}$ & Salina & $\begin{array}{l}\text { Capital } \\
\text { norteamericano }\end{array}$ & $\begin{array}{l}\text { Guerrero } \\
\text { Negro }\end{array}$ & 1957- & $\begin{array}{l}\text { Venta al } \\
\text { Gobierno y en } \\
\text { función }\end{array}$ & 13,054 & $\begin{array}{l}\text { Viviendas, } \\
\text { bodegas y faro }\end{array}$ & $\begin{array}{l}\text { Salina más grande } \\
\text { del mundo y } \\
\text { viviendas }\end{array}$ \\
\hline $\begin{array}{l}\text { Compañía } \\
\text { Occidental } \\
\text { Mexicana }\end{array}$ & Minería & $\begin{array}{l}\text { Capital } \\
\text { canadiense }\end{array}$ & $\begin{array}{l}\text { Isla San } \\
\text { Marcos }\end{array}$ & 1923- & En función & 650 & $\begin{array}{l}\text { Viviendas y } \\
\text { capilla de yeso }\end{array}$ & Patrimonio activo \\
\hline $\begin{array}{l}\text { International } \\
\text { Company of } \\
\text { México } \\
\text { Pacific Salt } \\
\text { Company } \\
\text { Southwest } \\
\text { Company of } \\
\text { Onyx and } \\
\text { Marbel }\end{array}$ & $\begin{array}{l}\text { Agro- } \\
\text { industria y } \\
\text { minería }\end{array}$ & $\begin{array}{l}\text { Capital } \\
\text { norteamericano } \\
\text { Capital Inglés } \\
\text { Capital } \\
\text { norteamericano }\end{array}$ & $\begin{array}{l}\text { Tecate } \\
\text { Isla del } \\
\text { Carmen } \\
\text { El Mármol }\end{array}$ & $\begin{array}{l}1884-1917 \\
1900-1984 \\
1889-1958\end{array}$ & $\begin{array}{l}\text { Mineral } \\
\text { agotado y la } \\
\text { agroindustria } \\
\text { en función } \\
\text { Abandonado } \\
\text { Abandonado }\end{array}$ & $\begin{array}{l}65,000 \\
0 \\
0\end{array}$ & $\begin{array}{l}\text { Estación del } \\
\text { ferrocarril } \\
\text { Infraestructura } \\
\text { salinera } \\
\text { Escuela }\end{array}$ & $\begin{array}{l}\text { Patrimonio activo } \\
\text { Muelle y edificios } \\
\text { en ruinas } \\
\text { Construcciones } \\
\text { industriales y } \\
\text { escuela } \\
\text { construida de } \\
\text { mármol }\end{array}$ \\
\hline
\end{tabular}




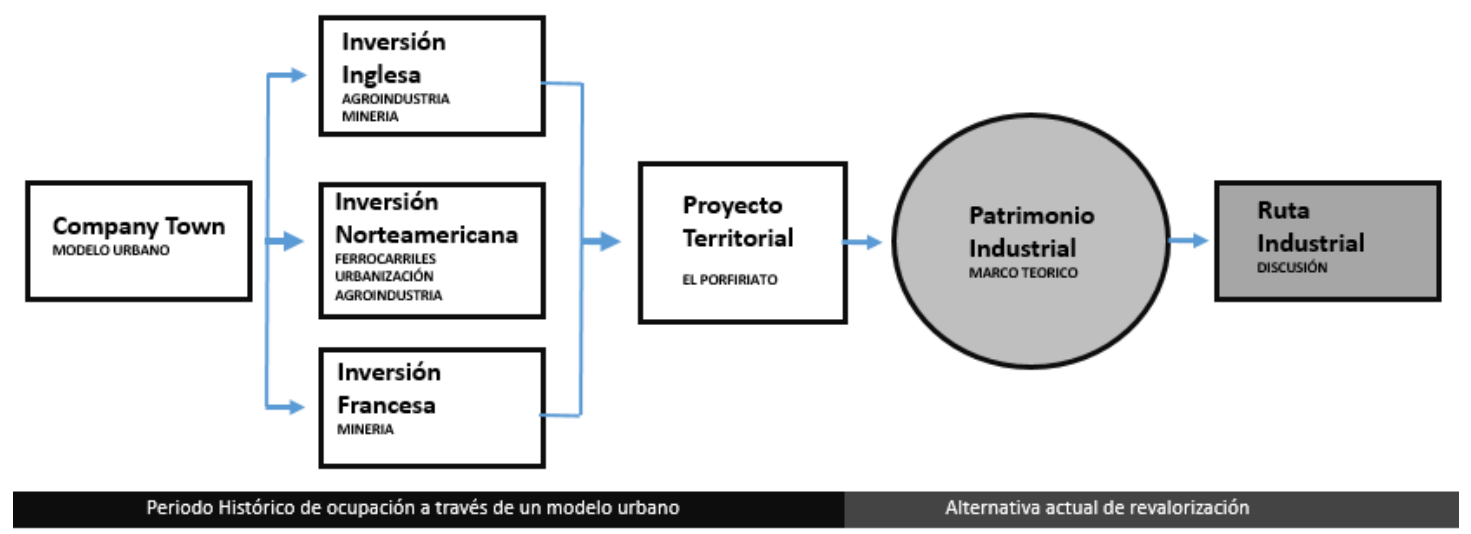

Figura 2. Esquema general de la estructura lógica de la información más importante que plantea la investigación. Fuente: Elaboración Propia.

Existen diversos y muy valiosos ejemplos de arquitectura, instalaciones, minas, fábricas, puertos, muelles, salinas, chimeneas, canales, puentes y pueblos enteros que pudieran ser considerados patrimonio industrial del país. Siendo la península de Baja California una de las menos pobladas del mundo, ha desarrollado una marcada identidad urbanística, diferente al resto de México. Se trata de comprobar que la fundación de estas poblaciones es un modelo de urbanización a través de la industria, valorar cuánto se consolidó y que tanto queda hoy en día de sus primeros trazados y vestigios industriales.

El análisis del urbanismo de las company towns empieza revisando los proyectos originales, lo que nos permite encontrar ejemplos de arquitectura industrial, verificar la variedad y adaptación de este modelo de urbanización; y como la construcción de 10 casos a lo largo de esta angosta península que ayudan a ocupar, podría ser en la actualidad, una ruta de patrimonio industrial que trate de reforzar su débil estructura territorial actual.

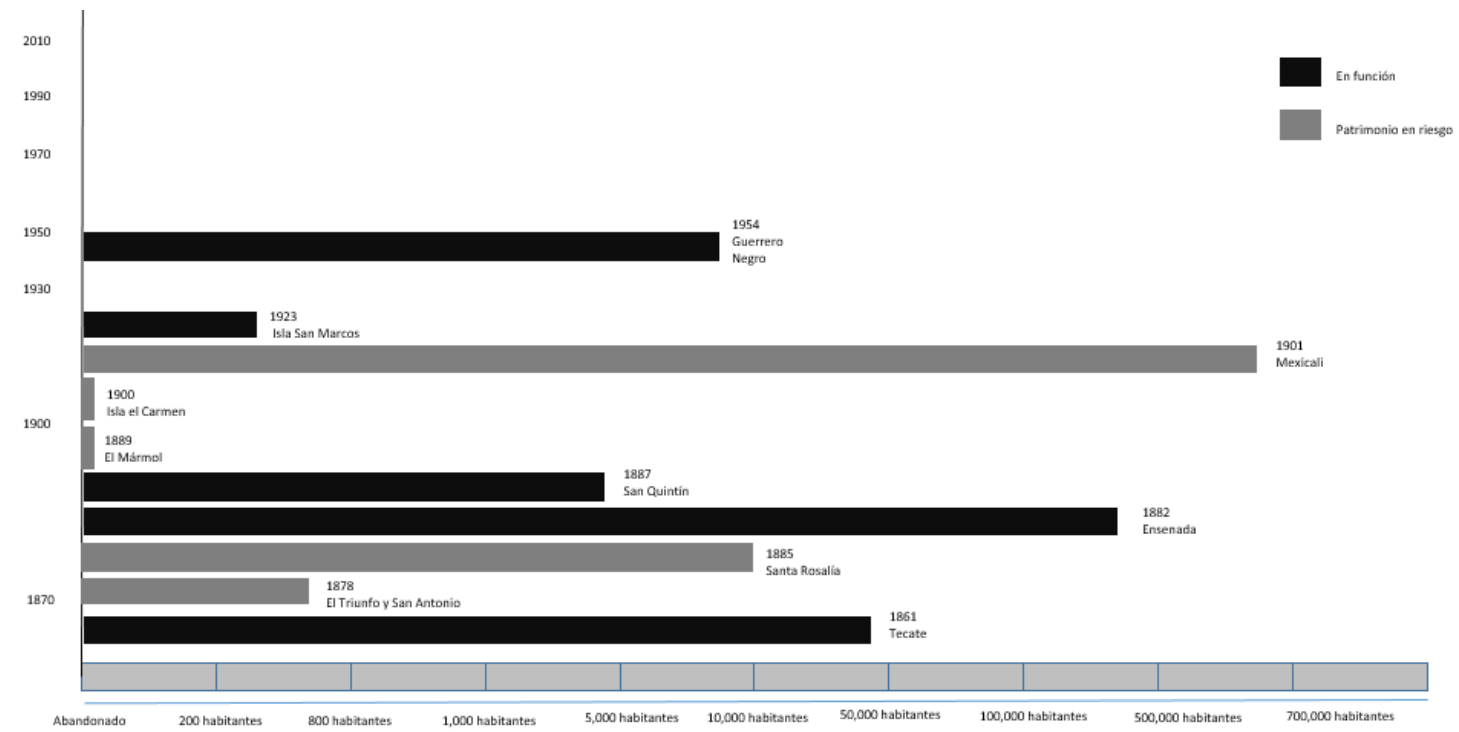

Figura 3. Gráfico donde se aprecian diez casos de estudio en relación a su población y su patrimonio en uso o riesgo de desaparecer. Hay seis casos que surgen en el Porfiriato. Tecate se funda en 1888, aunque antes ha sido colonia agrícola; El Triunfo y San Antonio, tienen un origen anterior al Porfiriato pero es en este periodo cuando hay una notable inversión extranjera en las minas y se consolidan las poblaciones industriales. Se identifican finalmente 2 casos después del periodo estudiado. Fuente: Elaboración Propia.

\section{Contexto histórico}

Varias son las causas que llevan a México a perder en 1848 los territorios del Norte (Alta California, Arizona, Nuevo México y Texas). La inestabilidad política y económica de esa época, aunada a la combinación de la escasa población y a la expansión de los Estados Unidos en la era industrial lleva a modificar los límites 
entre los dos países. A finales del siglo XIX el vecino del Norte comienza su penetración financiera en territorios mexicanos fronterizos. Esto lo aprovecha el gobierno mexicano a través de concesiones al capital extranjero, utilizando una arriesgada, pero inteligente estrategia de ocupación, obligando a las industrias interesadas en explotar suelo mexicano a construir poblaciones, tratar de urbanizar regiones y ordenar territorios, evitando así perderlos, como años atrás.



Figura 4. Fotografía de Porfirio Díaz en el Palacio Nacional en 1908. Fuente: www.mexico-sigloxx.tumblr.com

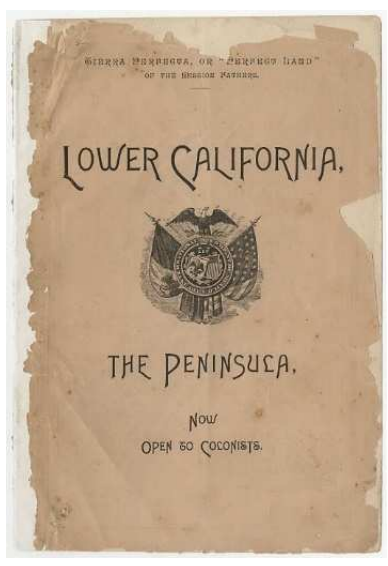

Figura 5. Lower California, the península, now open to Colonist: Tierra perfecta, the perfect land of the misión fathers. Portada del documento para promover la Baja California publicado en 1887 por Hanbury \& Garvey, Land Agents, San Diego California. Fuente: http://library.ucsd.edu/

Se puede decir que la península de Baja California empieza a desarrollarse urbanísticamente a través del modelo company town, lo que implica que durante el Porfiriato de 1876 a 1910 arranquen actividades en lugares prácticamente vacíos. La minería industrial, la agroindustria y la construcción de puertos, fábricas y bodegas implican que los capitalistas extranjeros no sólo deben construir instalaciones industriales, sino crear pueblos enteros para consolidarlas. Es importante mencionar que este fenómeno sigue dándose a lo largo del siglo XX en este territorio.

Los proyectos de las nuevas ciudades se desarrollan en función de su actividad económica. Arquitectos e ingenieros son contratados por los dueños de las compañías para diseñar poblaciones modelo, que van modernizando poco a poco un territorio inhóspito, aunque rico en recursos, localizados dispersamente en una península que es casi una isla, bien alejada del centro de México.

Figura 6. Fotografía de los inicios urbanos de Mexicali en la frontera norte de la Baja California en México. Fuente: Divulgación de las historias regionales de baja california (Dhiré).

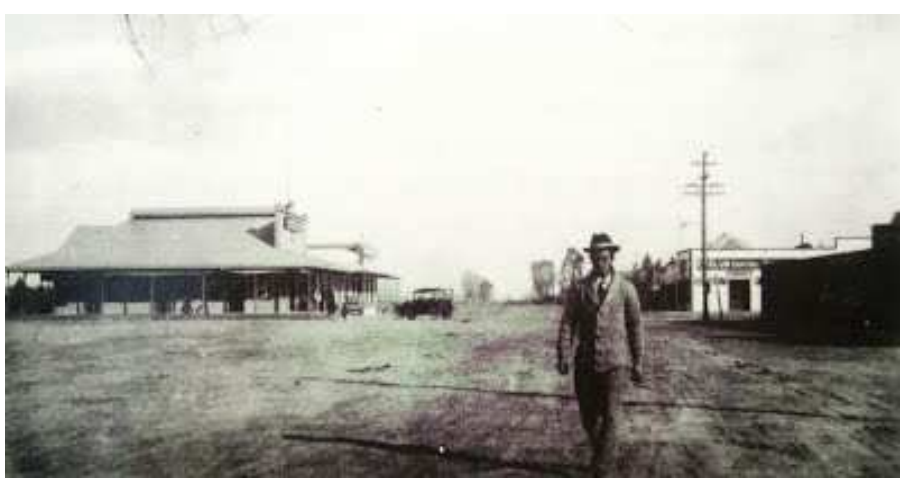

\section{El reparto de las concesiones territoriales al capitalismo extranjero}

Las concesiones territoriales otorgadas desde el gobierno de Benito Juárez entre 1857 y 1872 en la península de Baja California son un peligroso mecanismo para tratar de contrarrestar el abandono y la escasa población del ese delgado brazo de tierra, unido a la patria de milagro. Es verdad que los recursos naturales son saqueados y entregados a capitalistas extranjeros y que las perdidas territoriales comienzan con las invasiones económicas ${ }^{1}$. Pero también se puede ver a las concesiones territoriales como una estrategia mexicana para la activación económica y ocupación, eso sí, a muy alto precio de esta península tan alejada del centro del país.

\footnotetext{
${ }^{1}$ Libro El otro México, escrito por Fernando Jordán en 1956. Biografía de Baja California. Instituto de investigaciones históricas de Baja California. Tijuana México 2010.
} 
Figura 7. Cartografía de la costa baja californiana realizada por la Oficina Hidrográfica del Gobierno de Estados Unidos (NAVY). Estos planos están hechos con la intención de explorar las potencialidades de la costa e invertir en puntos estratégicos para establecer puertos y urbanizaciones. Fuente: Mapoteca Orozco y Berra.

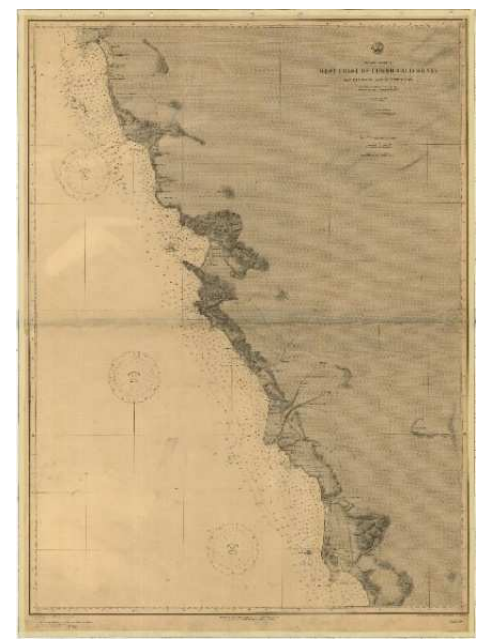

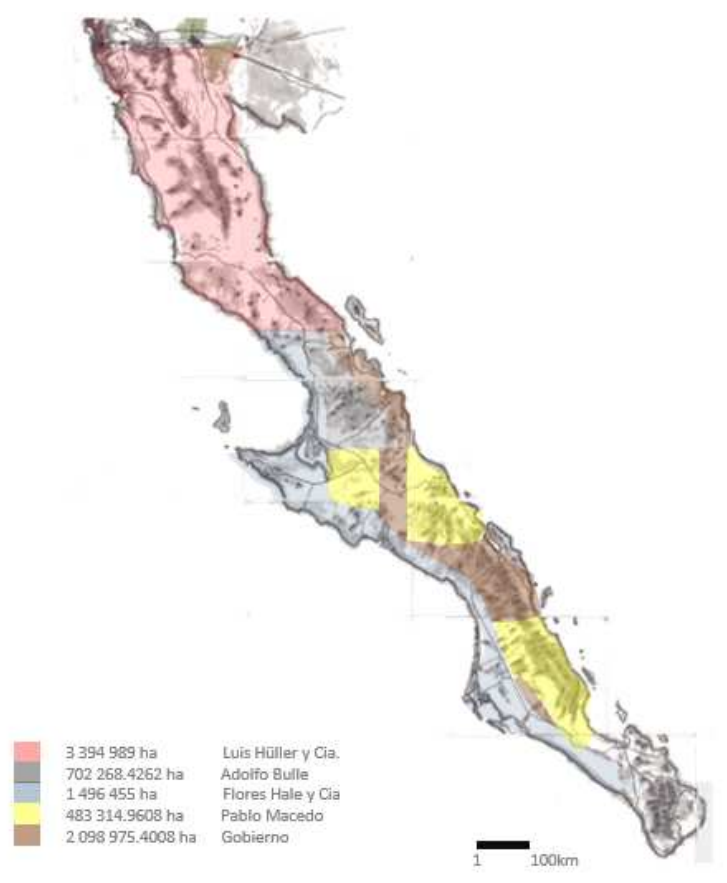

Figura 8. Dibujo de cómo queda repartida la península a través de diferentes concesiones territoriales al capital extranjero. Fuente: Elaboración propia en base al mapa de Ramón Alcorta, originalmente publicado por Luis Híjar y Haro. Tomado de la publicación El Otro México de Fernando Jordán.

La Ley de Colonización y Deslindes de Terrenos, promulgada en 1880 durante el Porfiriato, permite otorgar grandes contratos a particulares y a empresas con el fin de explotar los recursos naturales existentes en la península de Baja California, con el objetivo de favorecer el desarrollo productivo y la colonización de la zona.

Dentro del proyecto colonizador de Porfirio Díaz, la península de Baja California ocupa un lugar muy importante por lo escasamente poblado de su territorio. Las concesiones continúan con mucha fuerza en esta época, principalmente con el objetivo de ocupar y modernizar la península.

El resultado es que se incorpora este territorio a una economía mundial, abasteciendo principalmente a Estados Unidos con la fundación de ciudades dedicadas a la producción algodonera, salinera, la agroindustria y la minería, todas ellas de carácter exportador. Cabe mencionar que algunas de ellas se han convertido en ciudades modernas y prósperas que han consolidado la frontera; otras simplemente se han convertido en pueblos mineros fantasmas que al agotarse el mineral a mediados del siglo XX se resisten en desaparecer en ese paisaje peninsular de desierto y mar. 

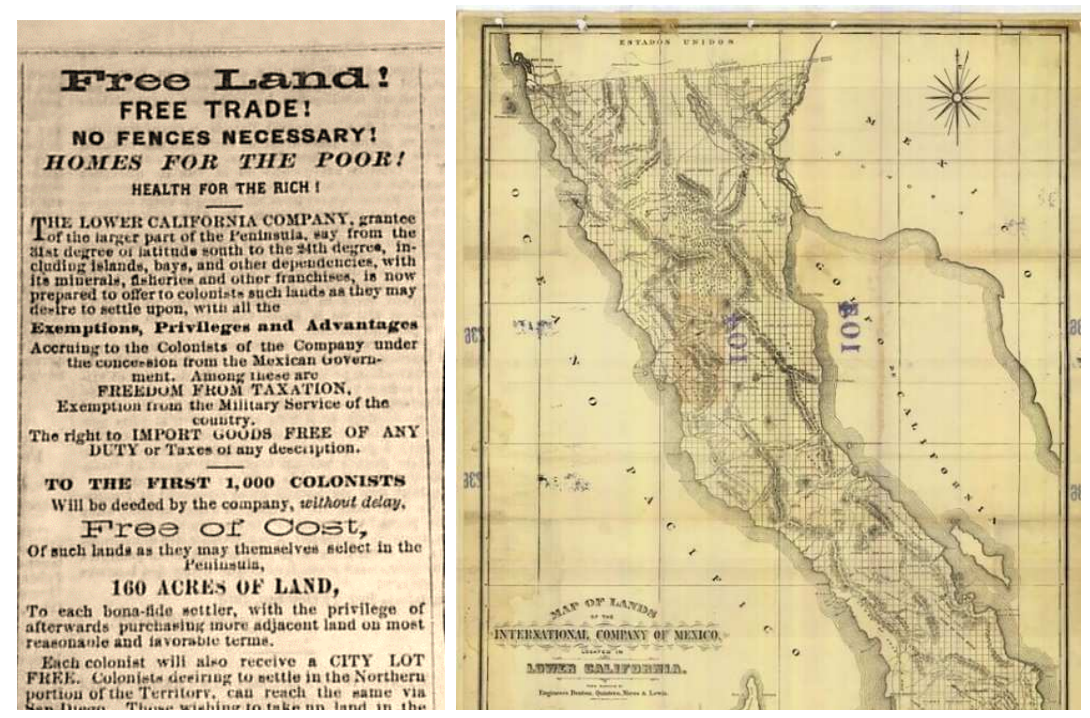
Figura 9. Mapa de la concesión territorial de $62.000 \mathrm{~km}^{2}$ que el gobierno mexicano otorga a la International Company of México en Baja California a finales del siglo XIX. Se aprecia la cuadricula de origen norteamericano para organizar el territorio. Fuente: Mapoteca Orozco y Berra, Ciudad de México colección general.

Figura 10. Noticias en los periódicos de California a finales del siglo XIX promocionando terrenos en Baja California.

\section{Las ciudades de las compañías}

En el Norte de México aparecen con la industrialización un nuevo tipo de formas urbanas que evolucionan al ritmo del nuevo capitalismo y de las nuevas tecnologías, desarrollando resultados sorprendentes. Se puede definir a la company town como un ideal que representa la transformación de la base económica de la nación americana y un modelo que interpreta el mito del primer capitalismo como una sociedad al servicio de la manufactura. Como modelo urbanístico representa una alternativa completa a la ciudad histórica, no tanto por la forma en que se estructura, sino por el hecho de incluir un nuevo elemento, la fábrica, buscando la máxima eficiencia productiva. ${ }^{2}$

Los ejemplos analizados presentan una clara influencia de modelos urbanos en su mayoría norteamericanos implementados por las compañías. Esta nueva forma de ocupación es una característica constante a pesar de sus variaciones y sin lugar a dudas una consecuencia para que esta región tenga una identidad urbana diferente al resto de México.

A pesar de que la Southern Pacific Railroad no puede extender sus conexiones ferroviarias al Sur de la península de Baja California a finales del siglo XIX, llega a tener mucha influencia con la vía fronteriza. EI ferrocarril trae una nueva manera de construir. Llegan nuevos materiales como la madera y el ladrillo, así como equipos y tecnología procedentes del medio oeste norteamericano. Al mismo tiempo, el ferrocarril se convierte en vehículo de modernidad arquitectónica. Se pasa de la construcción con adobe a la madera, vidrio y láminas de zinc. Se impulsa el sistema de construcción denominado "balloon frame", constituido con estructuras ligeras de madera. Se usan igualmente las fachadas y los edificios prefabricados, consolidando rápidamente los proyectos urbanos de las nacientes poblaciones ${ }^{3}$. Algunas estructuras de madera prefabricadas se transportan en embarcaciones desde la costa este de Estados Unidos antes del ferrocarril, recorriendo en embarcaciones el enorme continente americano por mar pasando por el Cabo de Hornos para llegar a la costa baja californiana en el Pacífico Mexicano.

\footnotetext{
${ }^{2}$ Definición de DAL, Co (1975). De los parques a la región. Ciucci, G. et al., La ciudad americana de la Guerra Civil al New Deal. Barcelona: Gustavo Gili.

${ }^{3}$ Ben Brown, Introducción e impacto del ferrocarril en el Norte de México. Universidad Autónoma de Ciudad Juárez 2009, pp. 231-236. Chihuahua, México.
} 

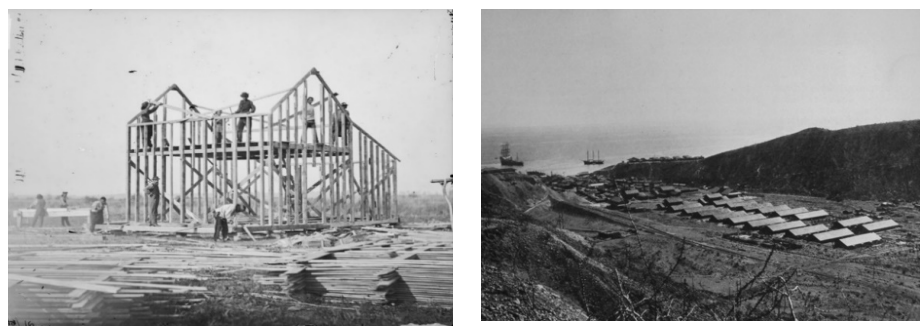

Figura 12. Fotografía del Capitán Harold Huycke. Inicios de Santa Rosalía, una ciudad del cobre diseña por el capital francés en la península de Baja California Sur, año aproximado 1898.

Figura 11. El sistema constructivo Balloon Frame está basado de estructuras prefabricadas de madera. Con este sistema de coloniza el Oeste norteamericano.

El extenso litoral de esta delgada península delimitada por sus dos mares, el Mar de Cortés o Golfo de California y el inmenso Océano Pacífico, es quizás otro motivo por lo que el proyecto del ferrocarril peninsular a finales del XIX no completa su llegada al Sur. Aquí es donde los puertos toman su vital importancia económica para exportar minerales y productos, ubicándolos en cualquier puerto del mundo, así como por ser el medio por donde llega gente, construcciones prefabricadas, y el equipo y maquinaria que se necesitan para empezar a echar andar las ciudades de las compañías. Esto último nos hace pensar que estas poblaciones no se articulan entre ellas por el territorio ya que la mayoría cuenta con acceso al mar y por el mar se conectan con otros puertos. Esta es una razón más, para pensar en su condición de enclaves que funcionaban independientemente en las diferentes localizaciones estratégicas donde surgen y que en algunos casos no fue precisamente la articulación territorial entre ellas lo que las caracterizó.
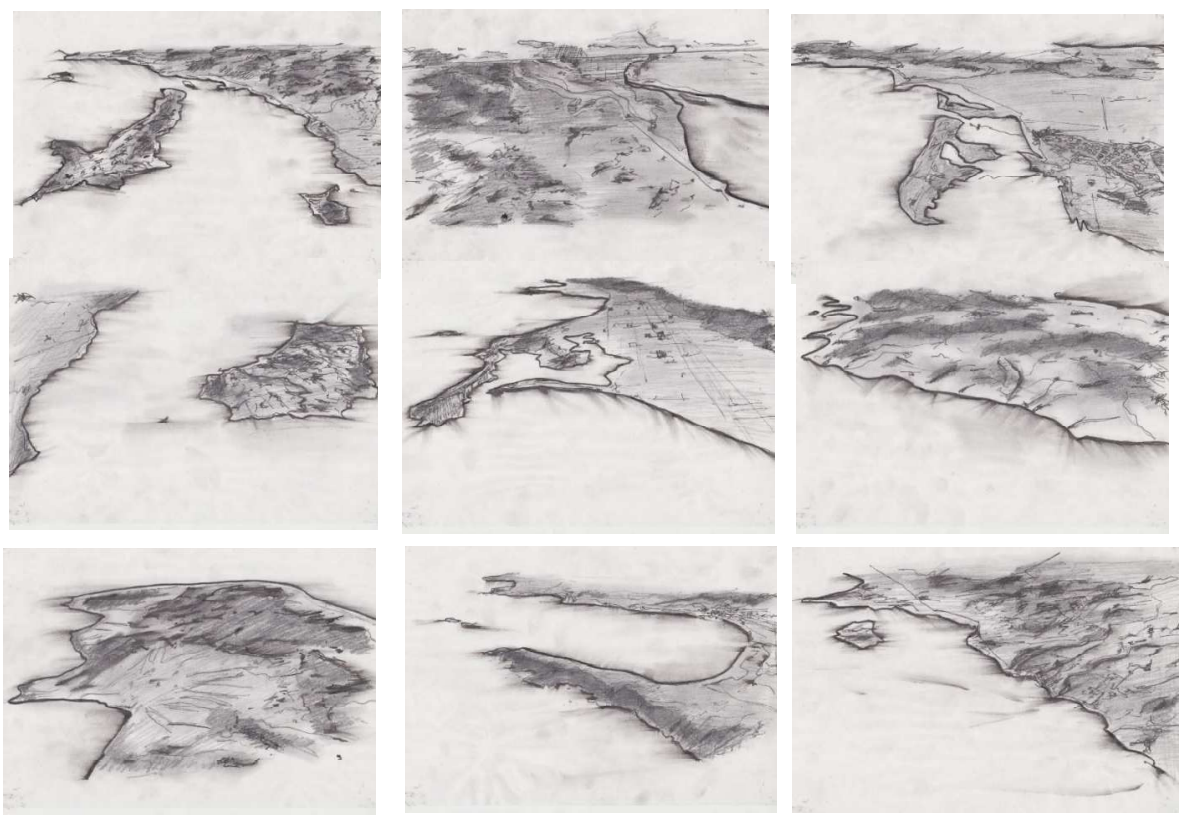

Figura 13.

Bosquejos de los litorales de la península de Baja California donde se establecieron los enclaves

industriales. Fuente:

Elaboración Propia 


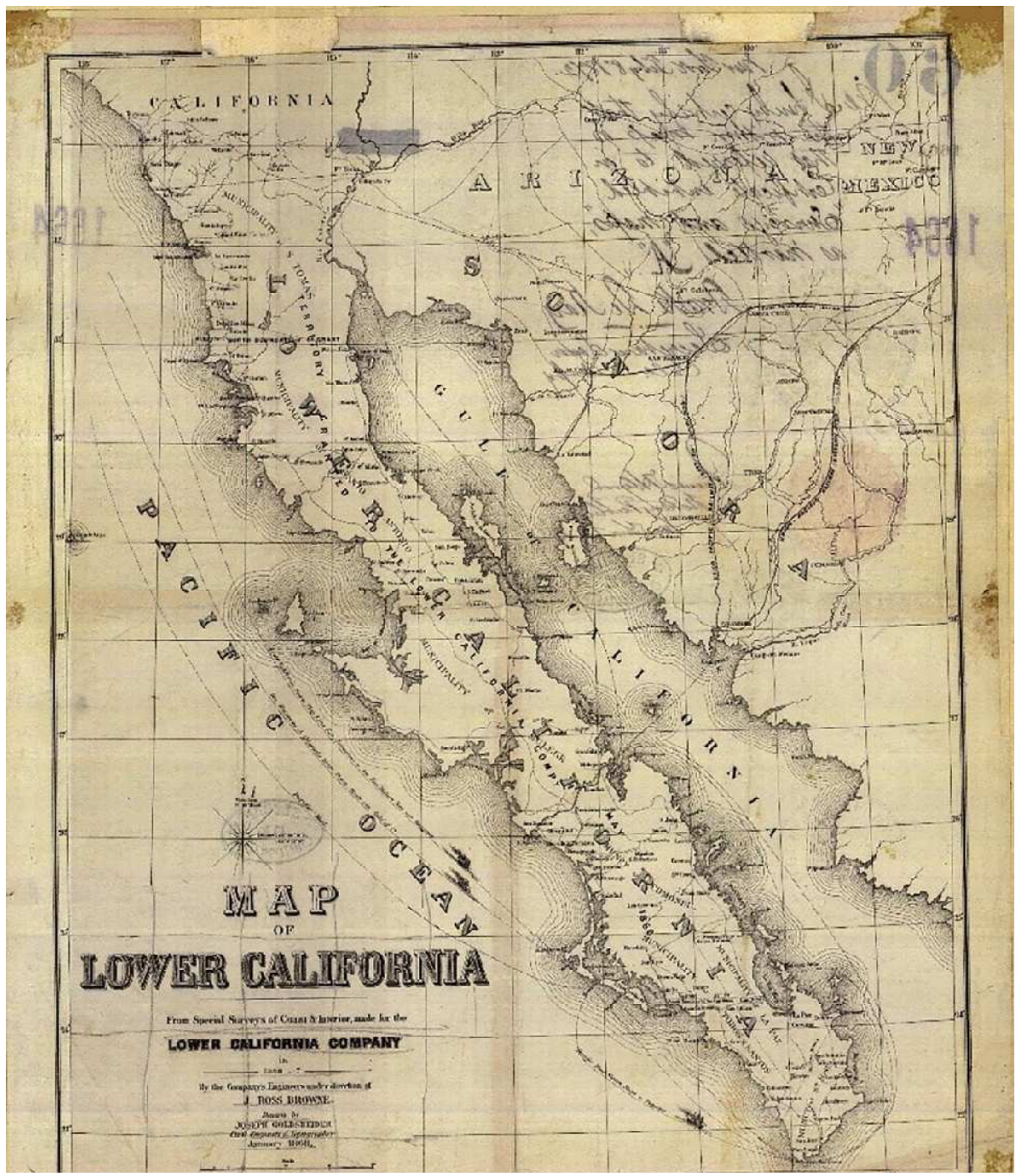

Figura 14. Mapa de la península de Baja California. La cartografía realizada por norteamericanos en este territorio fue una aportación muy grande a finales del siglo XIX. From special surveys of coast \& interior, made for the Lower California Company in 1866. By the companys engineers under direction of J. Ross Browne. Drawn by Joseph Goldsheider, civil engineer \& topographer, January 1868. Fuente: Mapoteca Orozco y Berra, Colección General.

\section{6. ¿Un proyecto territorial a través de la industria representado en 10 casos?}

\section{De colonia agrícola a ciudad industrial: Tecate}

Ya desde 1861 por decreto del Presidente Benito Juárez se muestra la intención de desarrollar la región estableciendo dos colonias, apareciendo en 1876 la colonia agrícola de Tecate, con plano del ingeniero Fiarco Quijano. Incluye un rectángulo de $33.500 \mathrm{~m}$ de largo, $10.475 \mathrm{~m}$ de ancho y una extensión de 35.112 hectáreas. ${ }^{4}$ Varios ranchos, sitios mineros y haciendas aparecen con la intención de empezar a poblar la frontera ubicada más al Norte, que México comparte con Estados Unidos. La fundación del pueblo se realiza en 1888 y su primer mapa data de 1892 y en 1908 llega el ferrocarril.

\footnotetext{
${ }^{4}$ Profile of the origins of Tecate's populations. Leticia Bibiana Santiago Guerrero. Libro, Tecate, Baja California: Realities and challenges in a Mexican Border Community. Editado por Paul Ganster, 2002.
} 

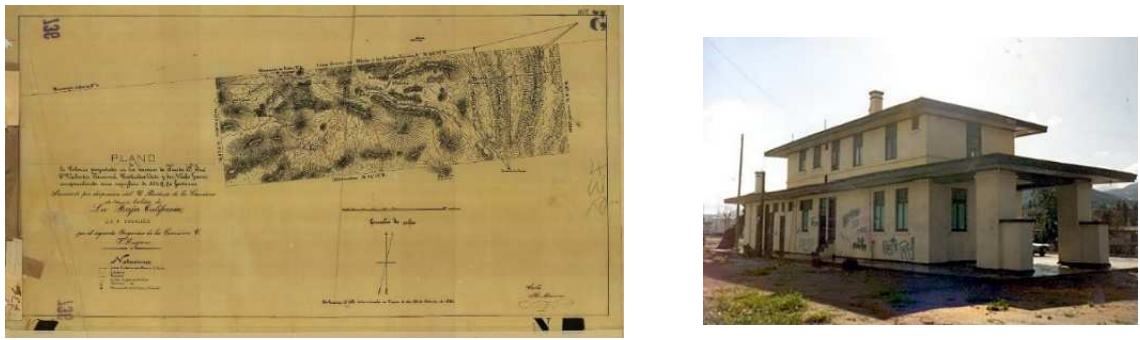

Figura 16. Fotografía de la estación del ferrocarril de Tecate, hoy catalogada como patrimonio industrial de Baja California por su historia y contribución al desarrollo industrial de la población

Figura 15. Plano de 1876 de la colonia agrícola proyectada en Tecate. 736-OYB-7221-A. Fuente: Mapoteca Nacional Orozco y Berra colección general.

a minería, la fábrica de malta, la siembra de cebada, el molino de aceite vegetal y las primeras bodegas de vinos son el motor económico para el desarrollo de la región. En los primeros planos, observamos un trazado de 21 manzanas, divididas en lotes de diferentes dimensiones; la manzana siete se divide en dos y ahí se construyen los edificios públicos y la plaza principal. En 1940 se amplía el fundo legal a 25 manzanas y actualmente Tecate tiene una población de 65.000 habitantes.

\section{Dos pueblos mineros fantasmas de la era industrial: El Triunfo y San Antonio} Se trata de dos reales de minas que llegan a ser en 1900 las poblaciones más grandes en toda la península. Aproximadamente a 1.000 kilómetros de la frontera con Estados Unidos

en el extremo sur de la península aparece en 1862 la Compañía Británica Gold and Silver Mining Co., que en pocos años establecen un sistema completo de extracción, concentración y fundición en la región donde se encontraba el pequeño real de minas de Santa Ana que desde mediados del siglo XVIII extraía los minerales de forma rudimentaria.



Figura 17. Plano de Tecate de 1979. Elaboración propia a partir de plano de la Subsecretaria de Asentamientos Humanos. Dirección General de Centros de Población.

Figura $18 . \quad$ Ruinas industriales en el Triunfo Baja California Sur. Fuente: www.bajachallengetours.com

Figura 19. Plano geológico minero de 1889 del real de San Antonio y El Triunfo de la Baja California. 217-CGE-7221A. Fuente: Mapoteca Nacional Orozco y Berra colección general.

Surgen después dos asentamientos cercanos a las minas del mismo nombre: San Antonio y El Triunfo a 7 kilómetros de distancia uno de otro. La compañía del Progreso Mining Company, de capital norteamericano, inicia la construcción en 1878 de un pueblo moderno dedicado a la minería industrial en el Triunfo.

La consolidación de las compañías entre 1878 a 1895 ayuda mucho a su crecimiento poblacional. Pero el auge dura poco, ya que en los primeros 10 años del siglo XX las dos poblaciones quedan abandonadas ${ }^{5}$. A finales del siglo XIX se construyen tiros y socavones que requieren de mecanismos más modernos. Se introduce la máquina de vapor en los túneles para el beneficio de los metales que se conectan a un circuito ferroviario entre las poblaciones. También se construyen fundiciones, puentes, vías, almacenes, bodegas, edificios administrativos y viviendas para los trabajadores.

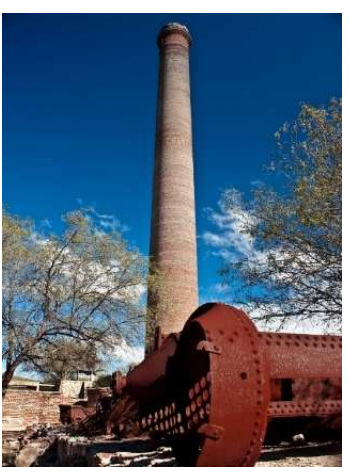

Figura 20. Fotografía de la chimenea de $47 \mathrm{~m}$ La Ramona, construida de 1876 a 1886 en El Triunfo.


Figura 21. Plano de 1870 del pueblo minero de El Triunfo. Fuente: Elaboración propia en base a los planos fundacionales.



Las construcciones son en su mayoría de finales del siglo XIX, vestigios de la minería industrial representadas en las dos chimeneas La Ramona y La Julia que siguen en pie y cuyo diseño se atribuye al francés Gustav Eiffel. Actualmente las dos poblaciones no llegan a los 800 habitantes y sus trazados urbanos y ruinas industriales están en grave deterioro, a pesar de los intentos en los últimos años del gobierno de Baja California Sur de incentivar la zona a través de programas de turismo cultural.


Figura 22. Esquema de reconocimiento urbano que nos muestra a través de la sobre posición de planos fundacionales y las fotos aéreas la poca consolidación del proyecto.

\footnotetext{
${ }^{5}$ Breve historia de los pueblos mineros de Baja California Sur. Una historia urbana de los pueblos de San Antonio y el Triunfo. Autores: Flor Barreto, Rocío Rochin y Gilberto Piñeda.
} 


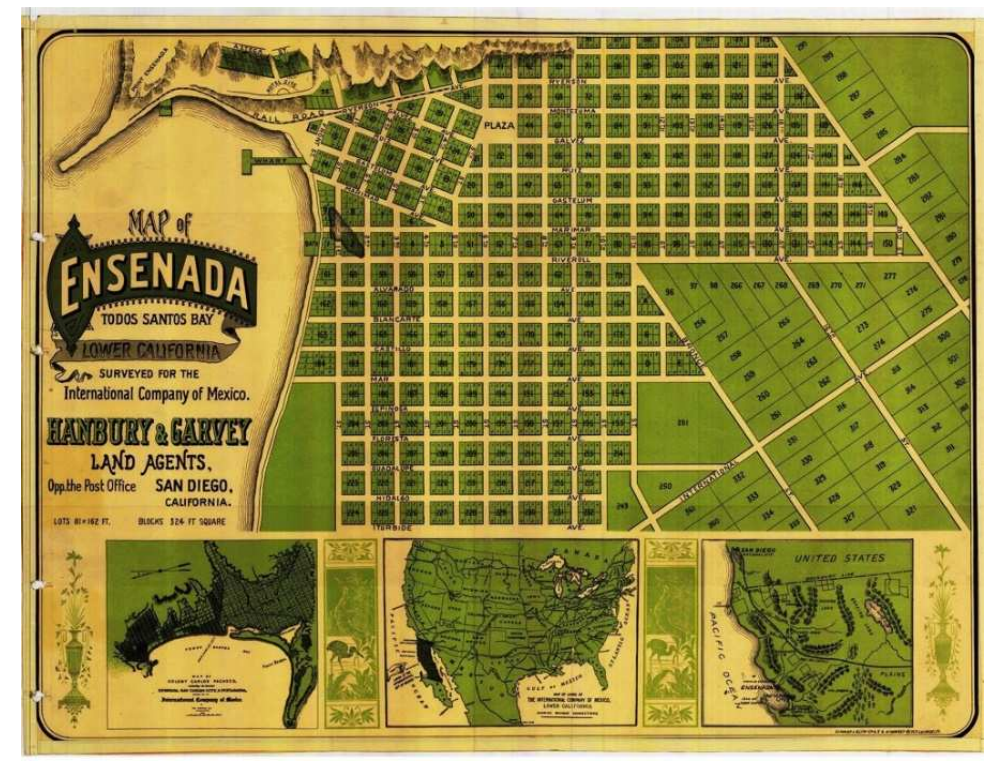

Figura 24. Plano de las lotificaciones del puerto de Ensenada realizado por la International Company of México en 1889. 739-OYB-7221-C. Fuente: Mapoteca Nacional Orozco y Berra colección general.



Figura 23. Fotografía del edificio de la International Company of México. A finales del siglo XIX, se inaugura en Ensenada este edificio de madera, de dos plantas estilo victoriano, construido en Inglaterra y armado en este puerto en el centro histórico. Fuente: www.inah.gob.mx y fotografía obtenida http://resena.ens.uabc.mx/

\section{El puerto más al Norte del Pacífico Mexicano: Ensenada}

En el año 1886, en los inicios del Porfiriato, se aceleran las concesiones territoriales a grandes capitales extranjeros, apareciendo el puerto de Ensenada con el propósito de atraer compradores norteamericanos a través de un ambicioso proyecto de urbanización en la costa del Pacífico por la International Company of México. Años después, esta compañía es adquirida por capital británico. Al mismo tiempo en el Sur de California se incrementa la venta de bienes raíces, fundamentalmente en las ciudades de Los Ángeles y San Diego y posteriormente se extiende al Sur de la frontera ${ }^{6}$. La traza urbana del puerto de Ensenada se hace siguiendo modelos de urbanización vigentes en ese entonces en Estados Unidos ${ }^{7}$. Se construye un muelle y algunas instalaciones como el edificio de oficinas de la compañía, unas viviendas de madera con estilos victorianos y un hotel. Se construyen bodegas de vinos, fábricas y un puerto por donde llegan las construcciones prefabricadas de madera, ya que aquí no llegó nunca el ferrocarril a pesar de estar a solo 100 kilómetros de la frontera con Estados Unidos. En la actualidad el Hotel Iturbide, que en su momento era un edificio singular de elegante estilo victoriano, ya no existe, pero si el edificio de la compañía que hoy es la sede de la Delegación de Ensenada del Instituto Nacional de Antropología e Historia.

Otro ejemplo es la reciente declaratoria de patrimonio cultural al conjunto arquitectónico de las bodegas de Santo Tomás, en la categoría de zona protegida modalidad de distrito urbano. El bien comprende 14 edificaciones de tipo industrial, constituyendo un valor histórico, cultural, social, arquitectónico y artístico.

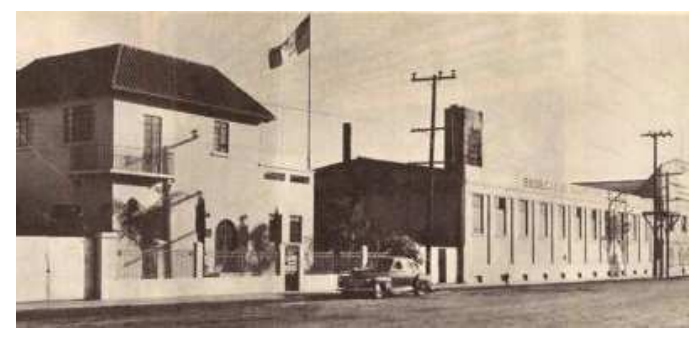

Figura 25. Bodegas Santo Tomás.

\footnotetext{
${ }^{6}$ Mencionado en el artículo de David Piñera y Alma Bejarano. Expresiones arquitectónicas compartidas en la frontera de Baja California y California. Revista Culturales, vol.7, no14, Mexicali 2011.

${ }^{7}$ Antonio Padilla Corona. (1998). "Inicios Urbanos del Norte de Baja California, Influencias e ideas, 1821-1906. Mexicali Baja California: Universidad Autónoma de Baja California. 1998.
} 
Las bodegas forman parte de la historia, costumbres y tradiciones de la ciudad, particularmente de la producción de vino, que brinda a Baja California un lugar privilegiado a nivel nacional en esta actividad. Las edificaciones están en las manzanas más antiguas y forman parte de la traza original desarrollada en el plano de 1886. Aquí, no solo los capitalistas extranjeros traen las ideas urbanísticas y trazan ciudades en territorio mexicano sino que también traen la arquitectura. Las primeras tiendas de artículos mineros, casas, negocios y escuelas se asientan y conforman un pequeño núcleo hasta que se expande el trazado de estilo americano con calles amplias y manzanas regulares, ya entrado el siglo XX.



Figura 26. Dibujo que muestra la mancha urbana actual de la ciudad de Ensenada y la retícula central que diseña la compañía. Fuente: Dibujos de Enrique Gómez

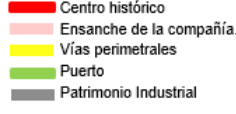

Hoy Ensenada es una ciudad de aproximadamente 520.000 habitantes y su puerto se consolida cada vez más con las conexiones con el continente asiático. Por eso es importante conservar las construcciones de los inicios industriales de la ciudad y valorar su identidad construida, ya que algunas se han demolido en los últimos años, borrando así nuestra memoria, que aunque reciente es muy valiosa.



Figura 29. Fotografía de la colonial industrial de El Mármol en 1953. Fotografía de Ralph Hancock
Figura 28. Fotografía de la escuela construida en mármol, lo único que queda de la colonia industrial. Fuente: Corredor Histórico CAREM, A.C. Fotografía de Ted Donovan

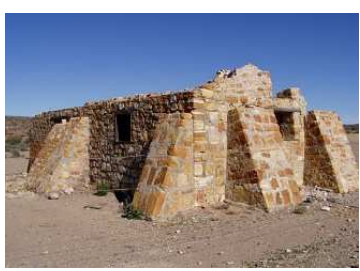




\section{La mina fantasma de onyx: El Mármol}

En 1889 se descubren unos ricos yacimientos, y la Southwest Company of Onyx and Marbel funda una pequeña colonia industrial y la New Pedrana Onix Company se encarga de la extracciòn y exportaciòn de todo el mineral a Estados Unidos. La mina de onix es la mas importante en el periodo industrial, ya que el $90 \%$ de este mineral que se vende en Estados Unidos viene de esta mina, la colonia industrial estaba localizada en una mesa (generalmente estos puntos elevados son el lugar donde se sitúan las áreas más privilegiadas de las company towns). ${ }^{8}$ Otro aspecto que muestra la relevancia de esta mina es que se establece un pequeño muelle con gruas y bodegas en la costa del Pacìico para la exportaciòn, transportando el mineral desde una distancia considerable. La mina cierra en 1958 y en la actualidad no existe casi nada, solo la escuela para los trabajadores construida con marmol y que bien podria considerarse una huella de la temprana industrialización Porfiriana, y aspirar a ser patrimonio industrial de Baja California.
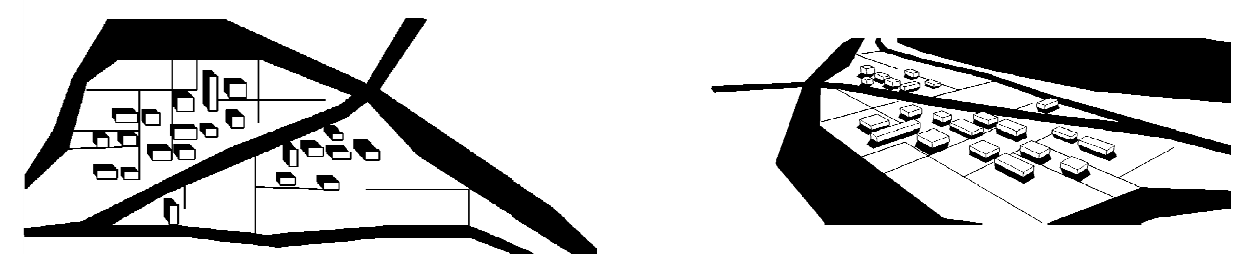

Figura 30. Actualmente estoy en proceso de consultar los planos de la colonia industrial, en este momento se han realizado esquemas y volumetrías para ir reconociendo la distribución urbana que tuvo la pequeña colonia industrial.

\section{Un pueblo francés en el desierto de Baja California: Santa Rosalía frente al Mar de Cortés}

En 1885 la Compagnie Du Boleo, de capital francés, construye el pueblo minero de Santa Rosalía, el primero en su tipo para la extracción y procesamiento de cobre en México.



Figura 31. Mapa de la región minera de Santa Rosalía, su mancha urbana y su circuito ferroviario de aproximadamente $40 \mathrm{~km}$ que conecta el sistema de minas al puerto. Fuente: The Economic Evolution of a Mining Community: Santa Rosalía, Baja California Sur, México. The Department of Geography Oregon State University, 1973. Plano realizado por Judith Cichowicz.

Figura 32. Plano actual del pueblo de Santa Rosalía. Elaboración propia.

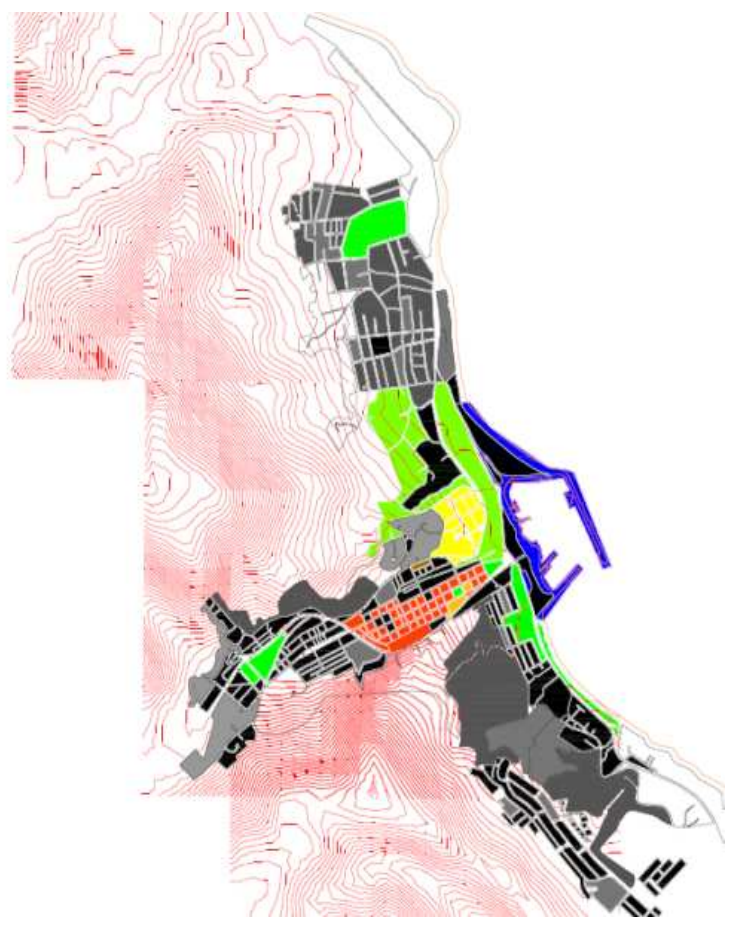

\footnotetext{
${ }^{8}$ Baja California, ¿el cuerno de la abundancia? Inversiones estadounidenses y desarrollo económico en el norte de la península, en el Porfiriato de Lawrence Douglas Taylor Hansen. Inversiones, colonización y desarrollo económico en el noroeste de México, 1870-1940. Autores: José Alfredo Gómez Estrada, Araceli Almaraz Alvarado. Editado por el Colegio de la Frontera Norte 2011.
} 
La ciudad presenta una segregación social evidente, además de condiciones laborales deudoras de la Revolución Industrial en el país. A mediados del siglo XX alcanza su apogeo económico. Sin embargo, el mineral empieza a agotarse ${ }^{9}$. La entrada al periodo post-industrial, la quiebra de la compañía son motivo para que en 1986 un decreto presidencial proteja 31 Monumentos Históricos a través del Instituto Nacional de Antropología e Historia. Santa Rosalía tiene en 1896 una población de casi 6.000 habitantes, y hasta 1940 no rebasa los 12.000 habitantes. Actualmente es un pueblo que se niega a morir, como explica Juan Manuel Romero Gil. Cuenta con 11.700 habitantes y encontramos ricos ejemplos de arquitectura industrial por doquier, la mayoría deteriorados o abandonados. Poco a poco se restauran algunos edificios, pero aún falta por recuperar el área industrial. El pueblo se mantiene en general en buenas condiciones.

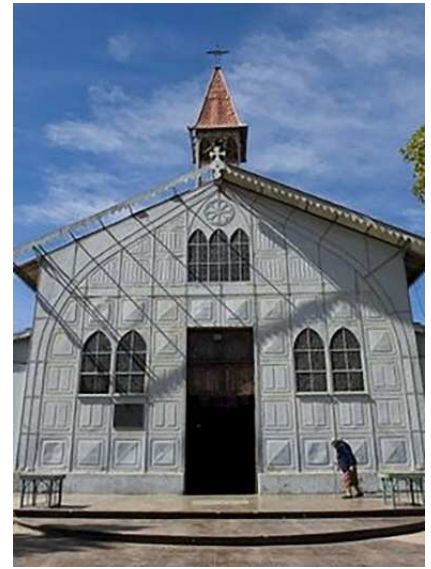

Figura 33. Fotografía de la Iglesia de Santa Bárbara construida de paneles metálicos. Fuente: Obtenida del artículo: La Iglesia "Eiffel" queda en Santa Rosalía, B.C.S. por Gustavo Zarza.
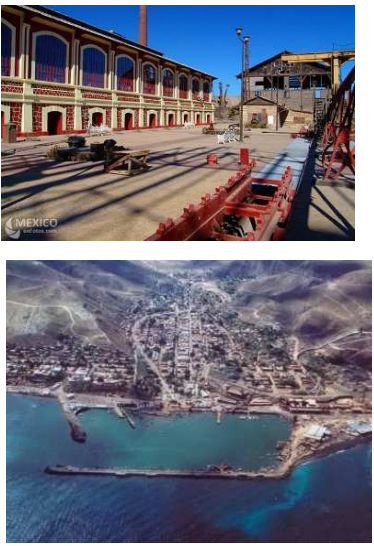

Figura 36. Fotografía de la zona industrial intervenida para museo y fotografía aérea del puerto de Santa Rosalía Baia California Sur

Figura 37. Plano de la estructura urbana principal del puerto. Elaboración propia

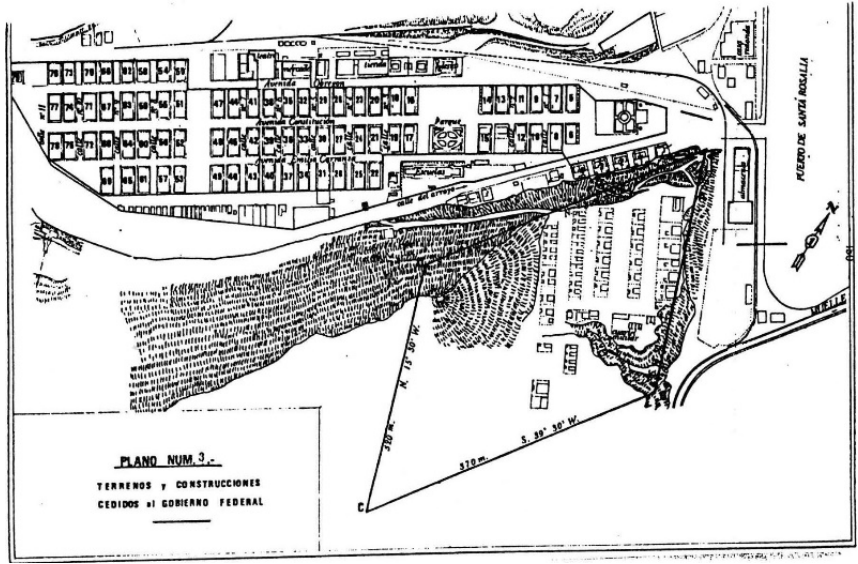

Figura 34. Plano de Santa Rosalía donde se muestra el polígono otorgado por la compañía al Gobierno Federal después de la Revolución Mexicana para establecer parte de la Mesa México. Fuente: Centro de estudios mexicanos y centroamericanos. El Boleo: Santa Rosalía, Baja California Sur, 1885-1954. Romero Gil Juan Manuel.

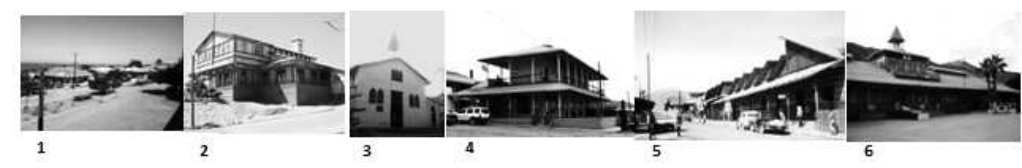

Figura 35.

Localización de edificios principales:

1.- Viviendas

2.- Edificio de la compañía

3.- Iglesia

4.- Hotel Francés

5.- Comercios

6.- Escuela



\footnotetext{
${ }^{9}$ Referente al caso de la company town de Santa Rosalía se presenta en 2014 una ponencia en el Primer Coloquio de Procesos de Industrialización en México organizado por el Instituto Nacional de Antropología e Historia con el título: El legado edificado y el patrimonio industrial olvidado. El Boleo en Santa Rosalía Baja California Sur.
} 
Aquí se encuentra la capilla de Santa Bárbara, una construcción expuesta en la exposición mundial de París en 1889 compuesta de paneles prefabricados de acero presuntamente del francés Gustav Eiffel. Hoy en día se mantiene en buen estado de conservación. La vocación económica del pueblo cambia al agotarse el mineral de cobre. Ahora la economía gira en torno a la pesca y la minería de cobre ha tenido un nuevo auge en los alrededores. Recientemente se ha llevado a cabo un plan turístico a cargo del FONATUR incluyendo al puerto en el Proyecto Mar de Cortés.

\section{6.- La Bahía de San Quintín: La capital frustrada de la compañía inglesa}

La misma International Company of México que proyecta el puerto de Ensenada cambia de dueños y ahora en vez de capital norteamericano pasa a ser de capital británico nombrándose Mexican Land and Colonization Company e inmediatamente proyecta sin mucho éxito el poblado de San Quintín en 1887 y se desarrolla una pequeña colonia de irrigación para el valle. Esta población pretende ser en esos años el centro para la compañía con interés del gobierno mexicano en ocupar estratégicamente el territorio. ${ }^{10}$ Durante los siguientes 20 años se consolidan obras como caminos y trazado urbano, una red de suministro de agua potable y el molino de harina más moderno de Latinoamérica, pero fracasó la conexión de la población por medio del ferrocarril con San Diego a 250 kilómetros de distancia, y solo se colocan 30 kilómetros de vía en San Quintín. También se realizan obras de acondicionamiento del muelle y el dragado de la bahía. En 1910 con la salida de Díaz del poder y el no reconocimiento por parte de líderes revolucionarios de los tratados firmados cambia el destino y en 1917 ya no queda casi nada del floreciente pueblo de San Quintín, dejando de existir durante más de 30 años.
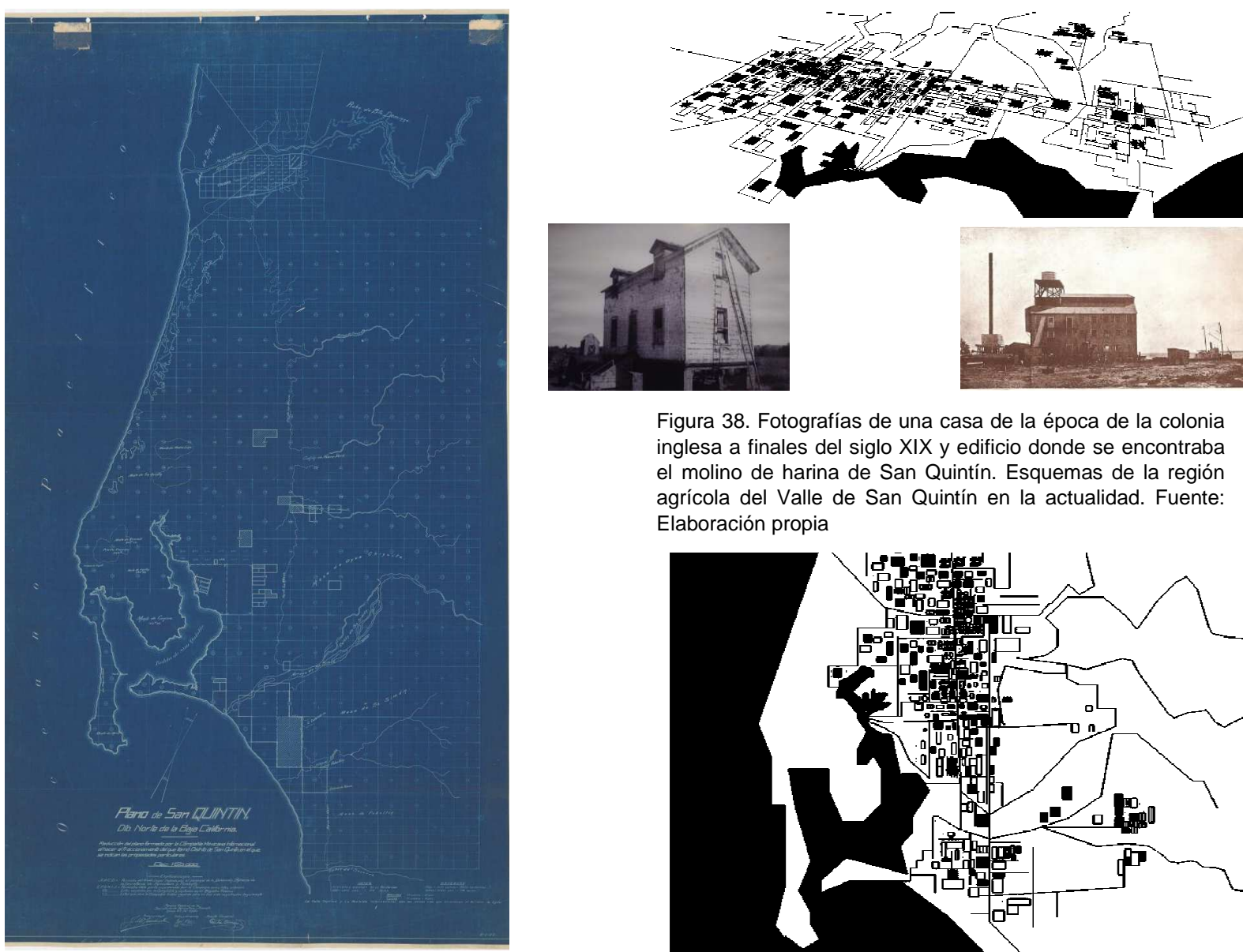

Figura 38. Fotografías de una casa de la época de la colonia inglesa a finales del siglo XIX y edificio donde se encontraba el molino de harina de San Quintín. Esquemas de la región agrícola del Valle de San Quintín en la actualidad. Fuente: Elaboración propia

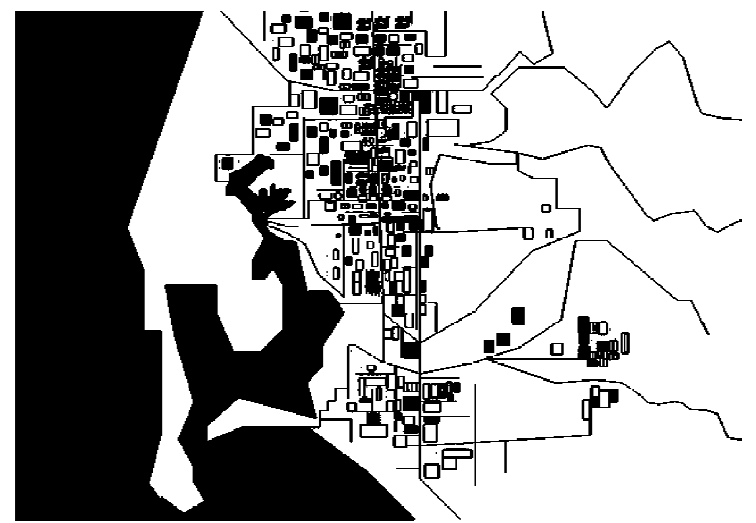

Figura 39. Plano de la ordenación territorial del valle de San Quintín a finales del siglo XIX. Fuente: Mapoteca Nacional Orozco y Berra colección general.

\footnotetext{
${ }^{10}$ Mencionado en el artículo de Hilarie J. Heath 2011 "El mal logrado proyecto del ferrocarril peninsular del Distrito Norte de la Baja California 1887-1892".
} 
Actualmente tiene una población de 5.000 habitantes, y se han desarrollado distintas poblaciones en los alrededores, creciendo el número de habitantes notablemente y dominando varias compañías agrícolas el valle. Se sabe de la existencia de construcciones industriales y la conservación del primer molino de harina en la región, con piezas de hierro forjado, propiedad de la compañía inglesa, desembarcadas en la Bahía de San Quintín y ensambladas a finales del siglo XIX.
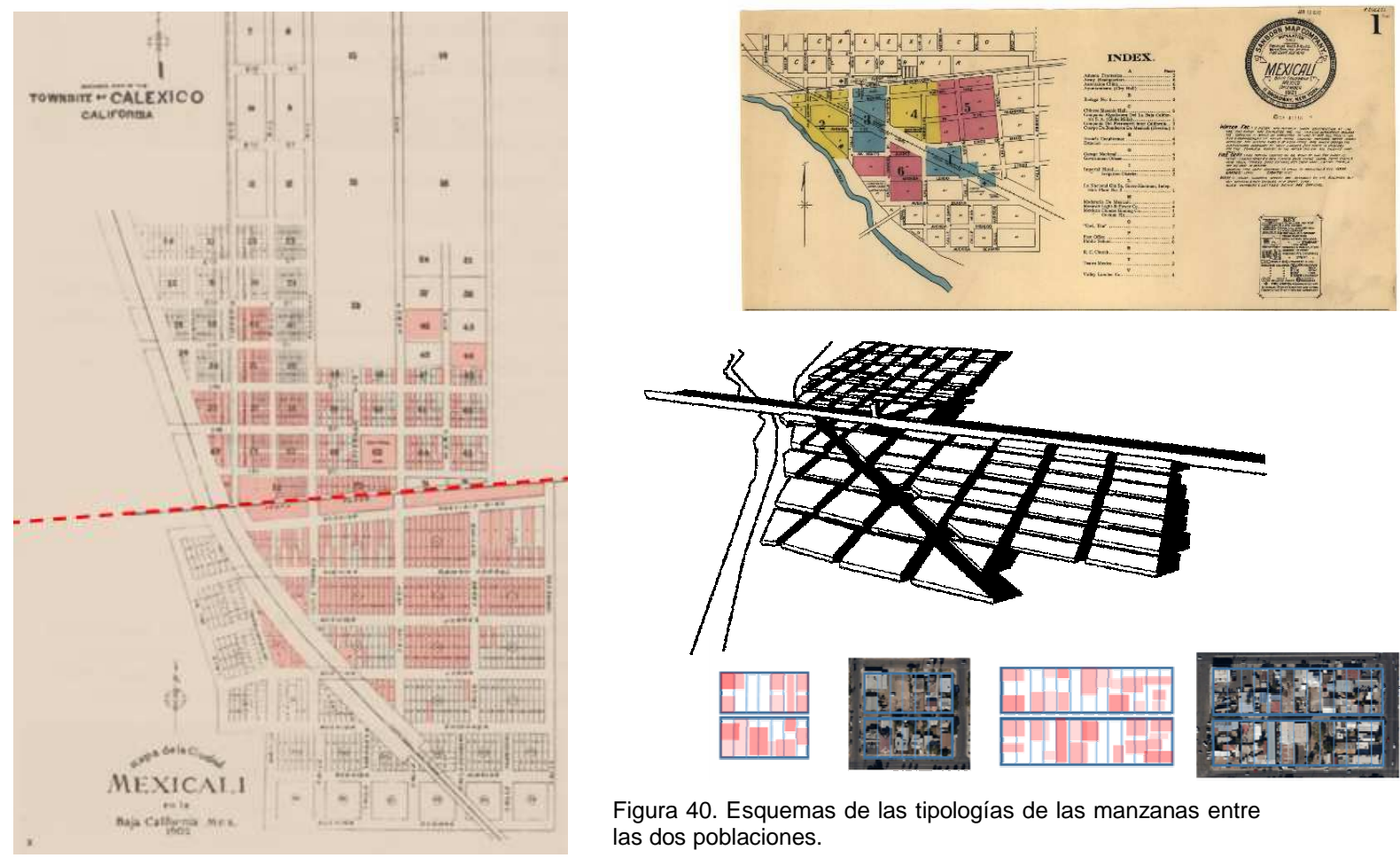

Figura 40. Esquemas de las tipologías de las manzanas entre las dos poblaciones.

Figura 41. Plano de 1902 de Mexicali en México y de Calexico en Estados Unidos que incluye las dos poblaciones. Se aprecia la frontera en línea horizontal y en línea vertical poco curveada la línea de ferrocarril. Lo interesante en este plano es el proyecto conjunto de la compañía entre los dos países. Fuente: Libro "Ciudades mexicanas del siglo XX" de Héctor Quiroz Rothe, editado por UNAM.

\section{7.- La ciudad de la compañía y su inmenso rancho algodonero: Mexicali}

A principios del siglo XX surge en la esquina noreste de la península de Baja California, en la región del delta del río Colorado, un próspero emporio agrícola de capital norteamericano. ${ }^{11}$ Es la Colorado River Land Company, que proyecta una exitosa colonia de riego al desviar por medio de canales el gran cauce del río Colorado en el valle de Mexicali en la frontera con Estados Unidos. Los dueños de la Colorado River Land Company son empresarios norteamericanos responsables del desarrollo del Sur de California. Entre ellos esta el general Harrison Gray Otis, propietario del influyente diario Los Ángeles Times ${ }^{12}$. La compañía diseña el trazado de Calexico en Estados Unidos como la colonia de los patrones, con edificios administrativos y viviendas. En Mexicali, en el lado mexicano se ubican las colonias de trabajadores, comercios, casas y bodegas. La población de Mexicali esta en sus inicios más conectada a Estados Unidos que a México, las vías de ferrocarril llegan en 1904 a cargo de la Southern Pacific Railroad y la compañía que se organiza desde 1902 se encarga de comprar y desarrollar las tierras hasta 1946, cuando vende las ultimas tierras después de la expropiación agraria de México en 1937. La compañía ha consolidado el rancho algodonero más grande del mundo.

\footnotetext{
${ }^{11}$ El valle de Mexicali y la Colorado River Land Company 1902-1946 de Dorothy Pierson Kerig

${ }^{12}$ El valle de Mexicali y la Colorado River Land Company 1902-1946 de Dorothy Pierson Kerig
} 


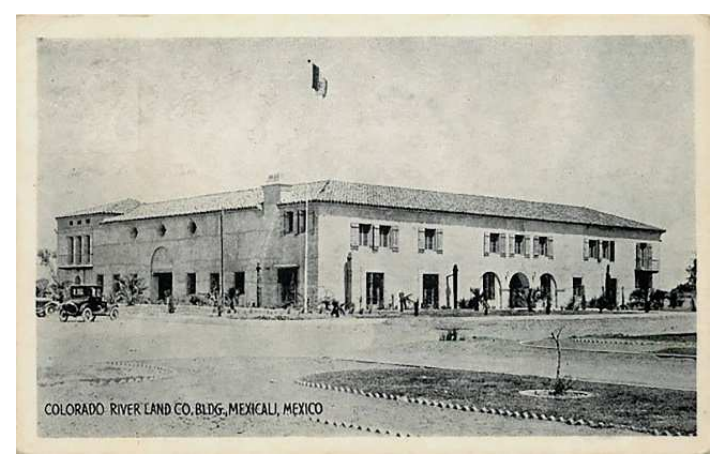

Figura 42. Edificio de la Colorado River Land Company construido en 1921 en Mexicali. Tiene una importancia histórica para Baja California ya que fue el detonador del desarrollo agroindustrial del Valle de Mexicali. http://www.mexicoenfotos.com/

Actualmente el edificio de la Colorado River Land Company y el edificio de la Cervecería Mexicali son el patrimonio industrial más reconocido actualmente por la ciudad, que cuenta con una población de 700.000 habitantes.

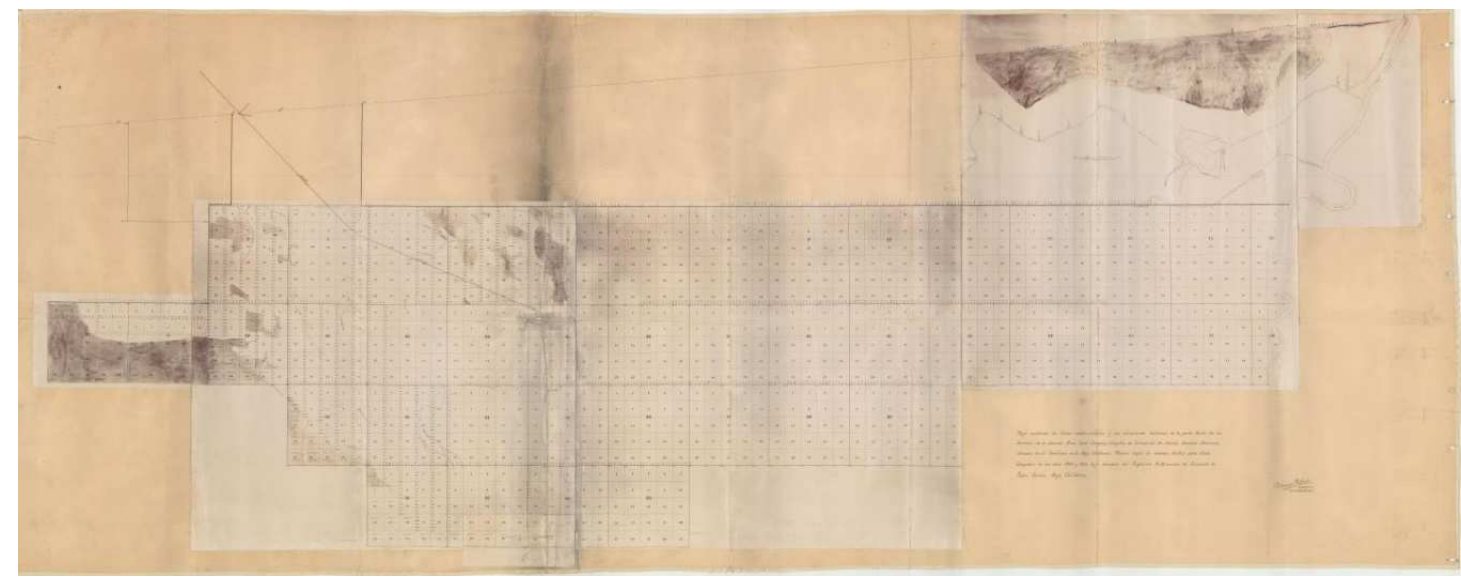

Figura 43. Mapa de finales del siglo XIX que muestra la lotificación cuadriculada que realizo el capital extranjero en la región agrícola de Mexicali. Fuente: Mapoteca Orozco y Berra.

\section{8.- La salina abandonada: Isla El Carmen}

De 1825 a 1860 hubo extracción rudimentaria de sal en la isla El Carmen. Pero no es hasta finales del siglo $\mathrm{XIX}$, cuando el gobierno mexicano otorga una concesion territorial a una compañia inglesa, la Pacific Salt Company Limited of London y es entonces cuando aparece una pequeña población. La compañia levanta viviendas para los trabajadores, un edificio corporativo, la escuela, el banco, el cementerio, edificios industriales, bodegas y una iglesia. En $1899 \mathrm{~J}$. R. Southworth escribe "... Existen además un ferrocarril que comunica las salinas con el muelle, compuesto de una locomotora y cuarenta carros, teniendo igualmente construidos recientemente, dos edificios de piedra y cemento, que se usan para oficina uno, mientas que el otro se ocupa con la maquinaria de moler sal, etc."13 Los trabajos industriales acaban en 1984 y hoy en día un viejo barco hundido en la bahía da la bienvenida junto a las ruinas del muelle y los edificios abandonados que son los vestigios que quedan en la isla y los restos de una identidad industrial perdida que conviene revindicar y documentar.

\footnotetext{
${ }^{13}$ John Reginald Southworth es un cronista estadounidense a quien Porfirio Díaz encomienda recorrer y describir un territorio que es prácticamente desconocido, la zona Noroeste de México. Su trabajo se traduce en ocho libros, los primeros son de la región noroeste del país y narran la situación que guarda Sonora en 1897, Sinaloa en 1898 y Baja California en 1899.
} 


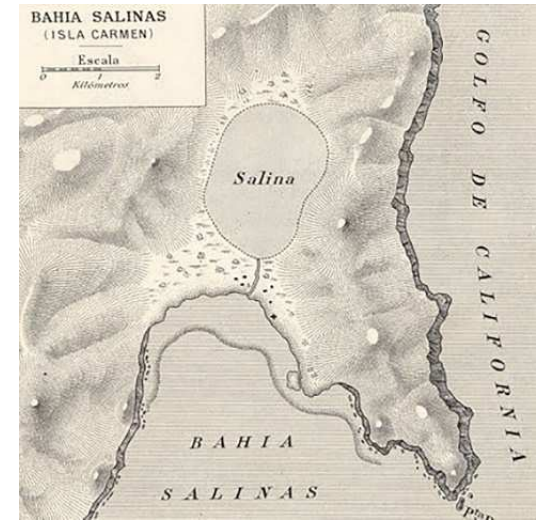

Figura 44. Dibujo de la salina de la isla El Carmen. Fuente: Fragmento de la obra de León Diguet, Territorio de la Baja California. Reseña geográfica y estadística (1912).

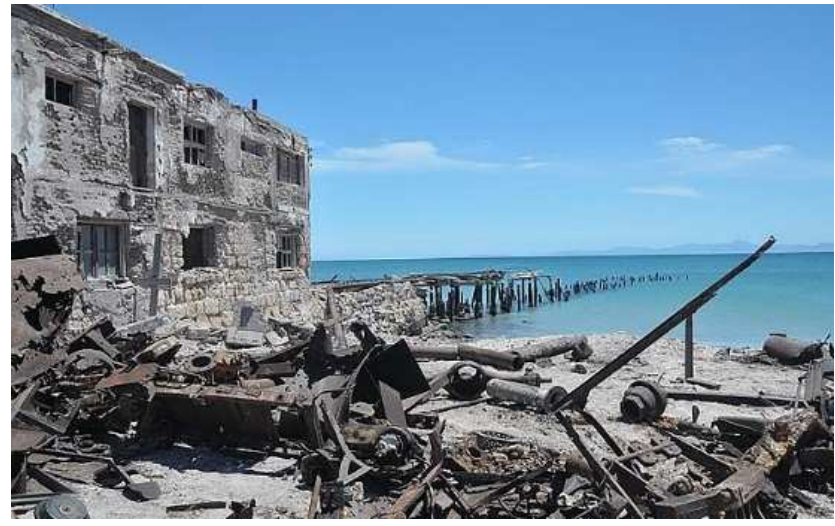

Figura 45. Fotografía de las ruinas del muelle de la isla El Carmen. Fuente: Fotografía de Geoffrey W. Schultz, 2012.

\section{9.- La isla de Yeso: Patrimonio industrial activo de la Isla San Marcos}

Los misioneros que recorren la península de Baja California mencionan en 1765 la existencia de una veta de yeso muy fino y transparente que sería difícil encontrar en otra parte y desde ahí se comenzó una pequeña extracción rudimentaria en la isla San Marcos en el Mar de Cortés. Existen datos que muestran que a finales del siglo XIX embarcaciones suecas y norteamericanas extraen yeso de la isla ${ }^{14}$. Pero no es hasta 1923, cuando se desarrolla un asentamiento planeado por la Compañía Occidental Mexicana, una colonia industrial para la explotación de yeso. Se construye una planta de electricidad y la infraestructura del muelle junto con las viviendas y una capilla construida de bloques de yeso que bien podría ser patrimonio industrial en el pequeño poblado. Actualmente la mitad del capital es canadiense y 400 personas habitan la isla. La isla San Marcos y su población son la primera exportadora de yeso de México y segunda a nivel mundial.

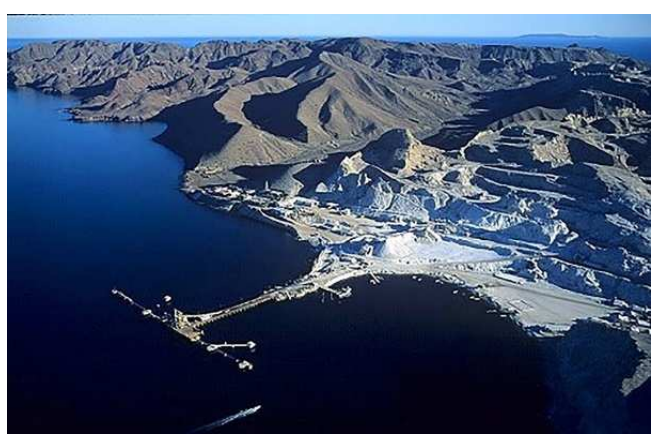

Figura 46. Fotografía aérea de la isla San Marcos en el Golfo de California. Fuente: http://www.airphotona.com/

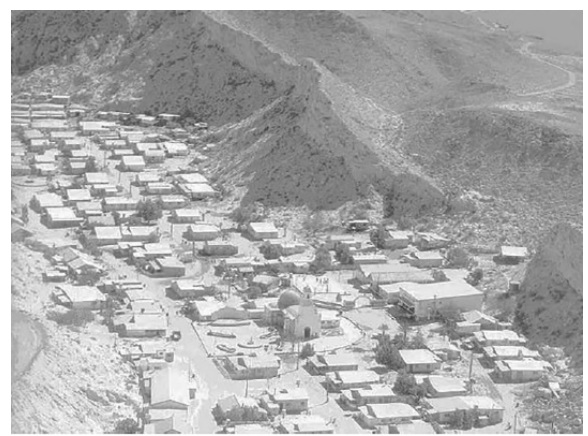

Figura 47. Fotografía de la colonia industrial en la Isla San Marcos

\section{0.- La visión de la salina más grande del mundo: Guerrero Negro}

El nombre de Guerrero Negro se dice que viene del nombre de un barco ballenero que se hundió cercano a la bahía Ojo de Liebre en 1858 llamado Black Warrior. En 1884 ya se extraía sal con sistemas rudimentarios, pero no es hasta casi 70 años después, en 1953, cuando un visionario norteamericano llamado Daniel K. Ludwig, dueño de una importante naviera, consigue ante la Comisión Mexicana de Fomento Minero una concesión territorial y funda en 1957 una salina para satisfacer primeramente la

\footnotetext{
${ }^{14}$ Breve historia de los pueblos mineros de Baja California, Isla San Marcos, un pequeño recorrido por su historia. Autores: Luis Larreta, Homero Avilés y Gilberto Piñeda.
} 
demanda de sal de la costa oeste de Estados Unidos ${ }^{15}$ y después del continente asiático. Ese mismo año empiezan a llegar los primeros trabajadores; la compañía construye varios campamentos, caminos y muelle para exportar la sal, así como la infraestructura industrial y una tienda. Hoy en día la Exportadora de Sal, S.A. de C.V. es la más grande del mundo y está enclavada en una orgullosa población minera de aproximadamente 15.000 habitantes, y produce un promedio de 7,5 millones de toneladas métricas anuales de sal marina, que exporta a diferentes países, principalmente a Japón y Estados Unidos ${ }^{16}$. Un ejemplo de company town moderno donde existen ruinas industriales como el viejo faro y las primeras bodegas y canales, al igual que el patrimonio industrial en activo.
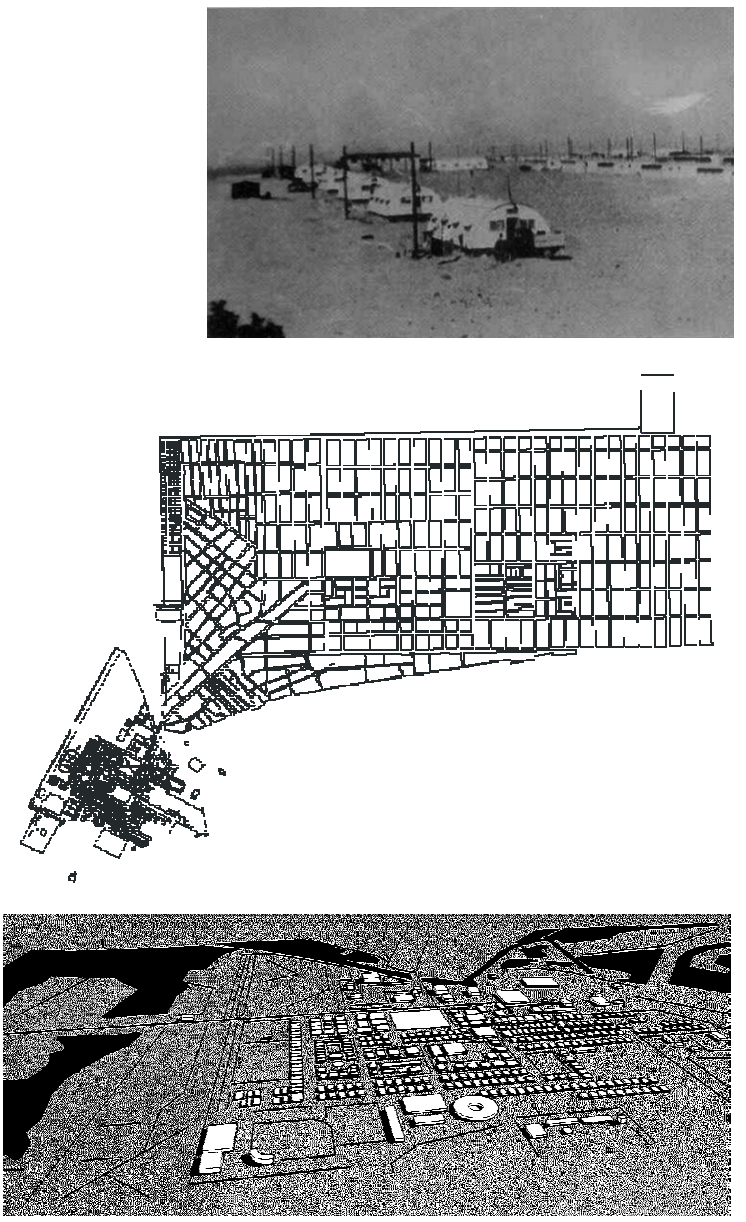

Figura 48. Fotografía de los colectivos y segunda vivienda para los trabajadores sindicalizados, de lámina de forma cilíndrica, daba alojamiento para dos familias en 1956. Se usaron colectivos prefabricados, los cuales habían sido utilizados como dormitorios por los norteamericanos, durante la segunda guerra mundial. Fuente: Crónicas de sal y arena http://www.guerreronegro.org/

Figura 49. Plano actual de la población de Guerrero Negro. Esta población surge para abastecer a la salina más grande del mundo, que se ha ido consolidando en el centro peninsular. Se puede apreciar una retícula regular ligada a un conjunto urbano más pequeño de operaciones y centro administrativo de la compañía.
Figura 50. Volumetría del trazado que aparece más cercano a la salina de Guerrero Negro, la retícula mencionada en el plano anterior es actualmente donde se establece el grueso de la población.

\footnotetext{
${ }^{15}$ Breve historia de los pueblos mineros de Baja California, Guerrero Negro, un pequeño recorrido por su historia. Autores: Bianca Gpe. Rodríguez y Gilberto Piñeda.

${ }^{16}$ Breve historia de la identidad minera peninsular y su aporte al desarrollo regional. La historia de la minería en Baja California Sur y su contribución al desarrollo social y económico de la entidad. Autor: Efraín Patiño.
} 


\section{Consideraciones finales}

Estos 10 casos de estudio muestran el desafío de ordenar y tácticas para poblar este territorio tan alejado del centro de México a través de enclaves industriales. Se puede decir que las company towns de la península de Baja California son en sus inicios modelos urbanos que sirven de herramienta para modernizar este territorio, a través de la industria a finales del siglo XIX y principios del XX.

Figura 51.
Fotografía de la
única carretera
transpeninsular
que recorre más
de $1.711 \mathrm{~km}$ y fue
terminada en
1973. La cual une
todos los casos de
estudio. Fuente:
Fotografía de
Enrique Gòmez
2013.

2013.
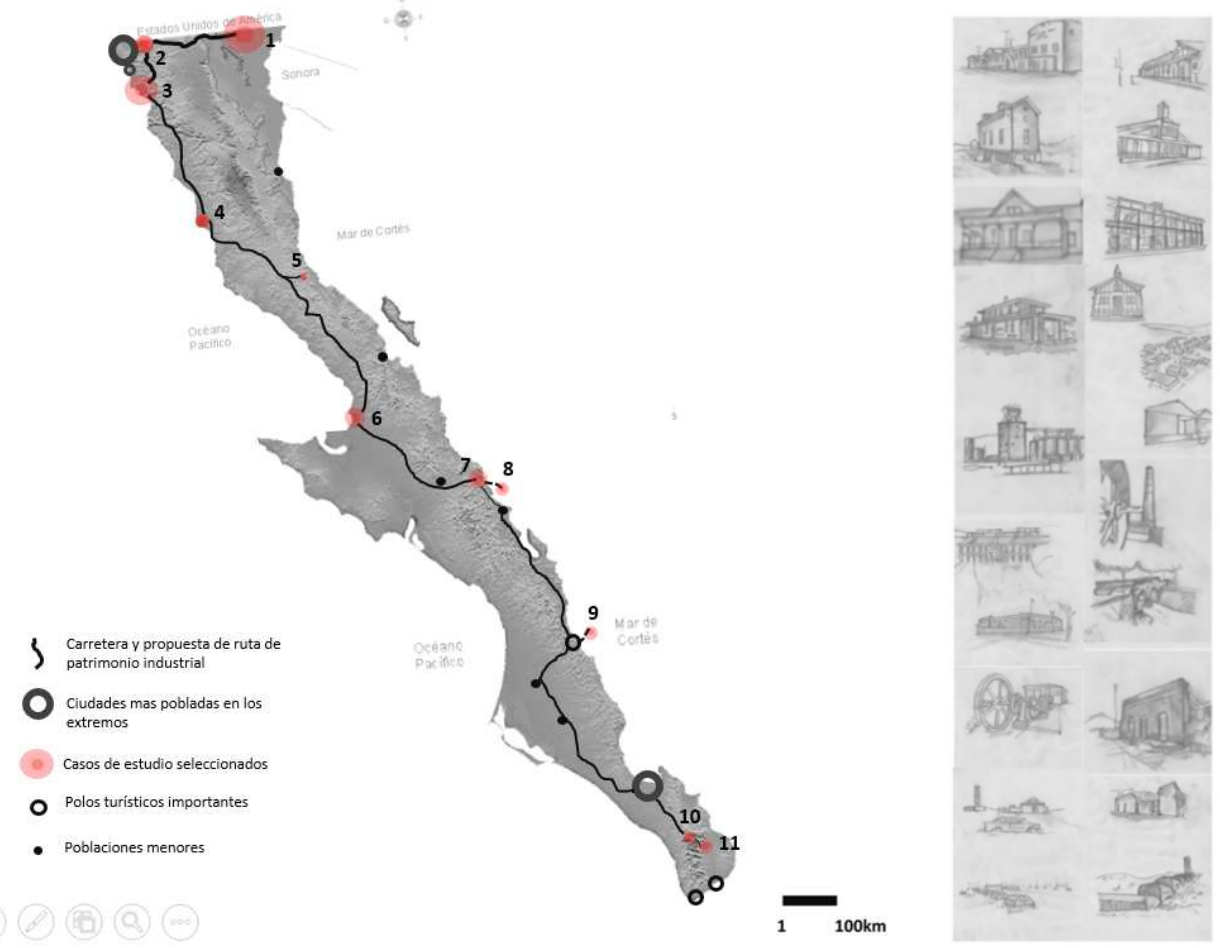

Figura 52. Esquema de la superficie de la península de baja california que cuenta con: $143.396 \mathrm{~km}^{2}$ y una población de: 4.321.552 millones de habitantes. Mapa modificado por el autor. En esta primera etapa se realizan bocetos de reconocimiento para representar la ruta industrial y los elementos patrimoniales en este territorio. Fuente: Enrique Gómez

1. Mexicali, 2. Tecate, 3. Ensenada, 4. San Quintín, 5. El Mármol, 6. Guerrero Negro, 7. Santa Rosalía, 8. Isla San Marcos, 9. Isla El Carmen, 10. El Triunfo, 11. San Antonio.

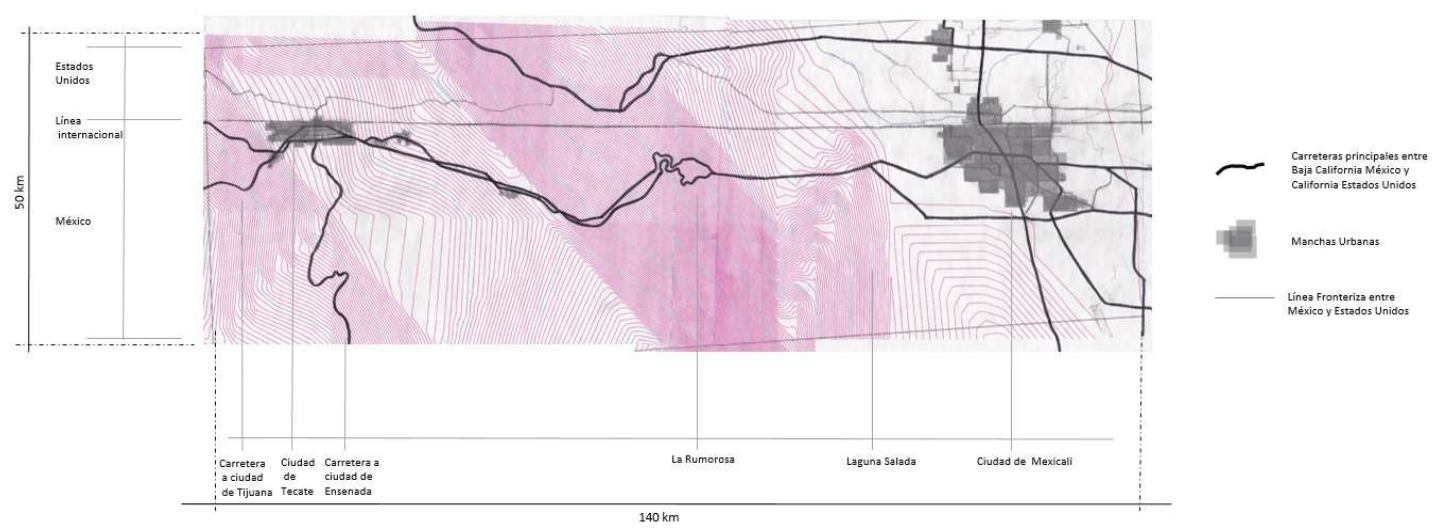

Figura 53. Ejemplo de solamente una región donde se localizan dos casos de estudio. Sección de $140 \mathrm{~km} \times 50 \mathrm{~km}$ del territorio Norte de la península de Baja California. Se muestra la estructura fronteriza actual entre las ciudades de Mexicali y Tecate en los límites de México y Estados Unidos. Con el objetivo de ver la dimensión territorial e identificar las manchas urbanas y sus conexiones. Fuente: Elaboración Propia 
Es interesante revisar las formas urbanas que aparecieron y el papel que jugaron en la ocupación del territorio. Pero creemos que más importante aún es la estrategia de este proyecto territorial del Porfiriato, de colocar a los diferentes capitales a lo largo del territorio, aprovechando a las industrias para construir poblaciones. Esto ocasiona que en este territorio se empiece a urbanizar de una manera diferente por medio de capitales extranjeros y que el soporte conceptual de las ideas de urbanización tengan características específicas sustentadas por los proyectos de las compañías y no vengan de la tradición urbana novohispana, sino de la división comercial del suelo, muy característica del vecino del Norte.
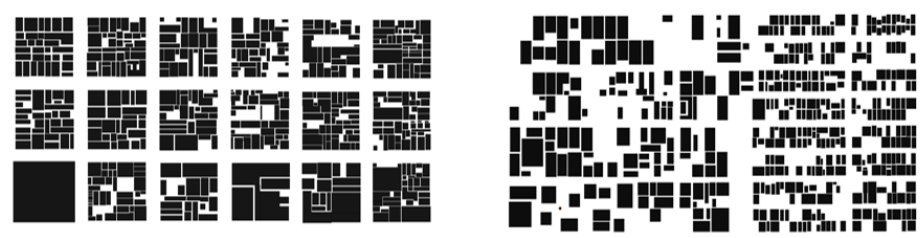

Sección de la población de San Quintín

International Company of México

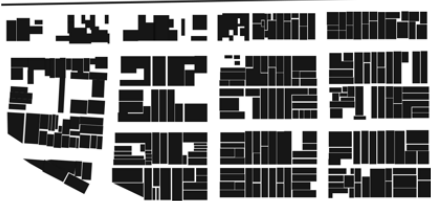

Sección de la ciudad de Mexicali

Colorado River Land Company



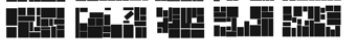



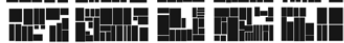

Sección de la ciudad de Tecate

International Company of México

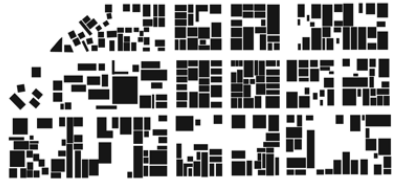

Sección de la población de Guerrero Negro Exportadora de Sal, S.A. de C.V

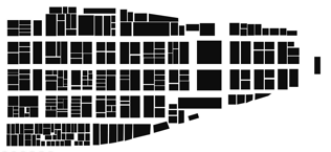

Sección del puerto de Santa Rosalía Compagnie Du Boleo



Población de Isla San Marcos Compañía Occidental Mexicana

$-1$



Figura 54. Esquemas de comparación de la forma urbana de los casos de estudio. Elaboración propia

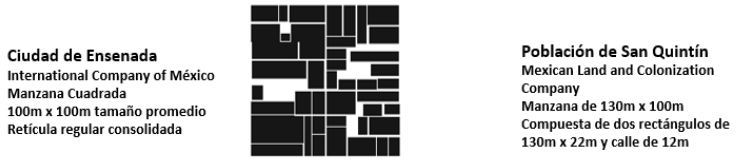



Población de Isla San Marcos Compañía Occidental Mexican ordenación aproximada no tan consolidada de
una manzana cuadrada de $25 \mathrm{~m} \times 25 \mathrm{~m}$ Wha manzana cuadrada de $25 \mathrm{~m} \times 25 \mathrm{~m}$



Población de Guerrero Negro Exportadora de Sal, S.A. de C.V Manzana cuadrada de
la reticula extendida

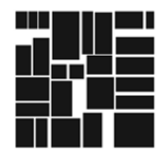

Salina de La Isla El Carmen Pacific Salt Company Limited of Londo seproxim recor aproximada no tan consolidada de u
manzana rectangular de $30 \mathrm{~m} \times 14 \mathrm{~m}$

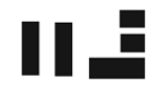

campuest

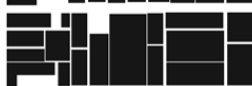

Ciudad de Tecate International Company of México Manzana de $126 \mathrm{~m} \times 110 \mathrm{~m}$ Compuesta de dos rectáng



Puerto de Santa Rosalí Compagnie Du Boleo 37 $37 m$ Compuesta de dos rectángulos de $37 \mathrm{~m} \times 17 \mathrm{~m}$

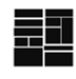

Población de El Triunfo El Progreso Mining Company Se reconoce una manzana
cuadrada de $110 \mathrm{~m} \times 110 \mathrm{~m} \mathrm{n}$ muy consolidada



Figura 55. Esquemas que muestran el tipo de manzana que se desarrolla en cada caso de estudio. Fuente: Elaboración propia. 
Hoy en día la situación es diferente, los trazados originales, las fábricas, minas y el rico patrimonio industrial del territorio peninsular están deteriorándose y requieren de una pronta valorización. Este trabajo busca mostrar el estado de los trazados urbanos actuales, para en un futuro poder plantear como propuesta una ruta patrimonial de company towns en la península de la Baja California, un itinerario industrial capaz de reforzar la estructura territorial y con ello la valorización de un legado construido desapercibido, que no se ha aprovechado y que, además, cuenta con un enorme potencial. Las rutas culturales en territorios postindustriales han sido en los últimos 35 años marco de reflexiones urbanas y territoriales muy interesantes, y están siendo capaces de revertir situaciones de abandono a través del turismo cultural en todo el mundo.

\section{Bibliografía}

ALVAREZ, Miguel Angel (2010). "La herencia industrial y cultural en el paisaje: Patrimonio Industrial, Paisaje y Territorios Inteligentes". Revista Labor y Engenho ISSN:2176-8846. V.4, n.1,2010. p.78-100. Campinas Brasil 2010.

BURIAN, Edward (2015) "The Architecture and Cities of Northern Mexico from Independence to the Present". University of Texas Press

BUSTO, Karina (2015). “Historical Archaeology of Baja Califronia Sur" Pacific Coast Archaeological Society Quarterly 51(3\&4):91-116

DIGUET, León (1912). Territorio de la Baja California, reseña geográfica y estadística, México. Librería de la Vda. De C. Bouret París-México.

ENGELKING, Sigismundo (2014). “Una especie en extinción, la arquitectura industrial del siglo XX; la industria en la zona metropolitana de la ciudad de México y su entorno urbano" Primer coloquio nacional: Los procesos de industrialización en México. INAH. 2014

GERHARD, Peter y Howard E. GULICK (1956). "Lower California Guidebook. Arthur H. Clark, Glendale, California.

GOMEZ, Aurora (2011). From Company Towns to Union Towns. Textile Workers and the Revolutionary State in México. The University of Georgia Press

HEATH, Hilarie (2011). "El malogrado proyecto del ferrocarril peninsular del Distrito Norte de la Baja California, 1887-1892". Estudios fronterizos. Versión impresa ISSN 0187-6961. vol.12 no.24 Mexicali jul./dic. 2011

JORDÁN, Fernando (1956). "El otro México". Biografía de Baja California. Instituto de investigaciones históricas de Baja California. Tijuana México 2010.

KRAUZE, Enrique (1987). "Místico de la autoridad, Porfirio Díaz", México, Fondo de Cultura Económica, pp.103 (Biografía del Poder, 1), México D.F. 1987.

MENDEZ, Eloy (2000). "Ciudades y arquitecturas del noroeste mexicano" Revista Región y Sociedad / Vol. XII / No. 20. El Colegio de Sonora. Hermosillo, Sonora. 2000.

MORALES, Humberto (2014) "Dossier Company towns" Labor \& Engenho, Campinas [Brasil], Editorial I\&e, v.8, n.4, Red Conpadre - México 2014

PADILLA, Antonio (1998). "Inicios Urbanos del Norte de Baja California, Influencias e ideas, 1821-1906. Mexicali Baja California: Universidad Autónoma de Baja California. 1998. 
PIÑERA, David, BEJARANO, Alma. (2011). “Expresiones arquitectónicas compartidas en la frontera de Baja California y California". Revista Culturales, vol.7 ,no14, Mexicali 2011.

SABATÉ, Joaquín (2004). Paisajes Culturales. El patrimonio como recurso básico para un nuevo modelo de desarrollo. DU Y OT. Urban 9. Primera época. p 8-29 